\title{
PROPHYLACTIC CLIPPING AFTER COLORECTAL ENDOSCOPIC RESECTION PREVENTS BLEEDING OF LARGE, PROXIMAL POLYPS: META-ANALYSIS OF RANDOMIZED TRIALS
}

Short title: Prophylactic clipping for PPB prevention

\author{
Authors \\ Marco Spadaccini ${ }^{1,2^{*}}$, Eduardo Albéniz ${ }^{3 *}$, Heiko Pohl ${ }^{4}$, Roberta Maselli ${ }^{1}$, Viveksandeep Thoguluva \\ Chandrasekar $^{5}$, Loredana Correale ${ }^{1}$, Andrea Anderloni ${ }^{1}$, Silvia Carrara ${ }^{1}$, Alessandro Fugazza ${ }^{1}$, \\ Matteo Badalamenti ${ }^{2}$, Mineo Iwatate ${ }^{6}$, Giulio Antonelli, ${ }^{9}$ Mónica Enguita-Germán ${ }^{3}$, Marco Antonio \\ Álvarez ${ }^{7}$, Prateek Sharma ${ }^{5}$, Douglas K. Rex ${ }^{8}$, Cesare Hassan ${ }^{9 * *}$, Alessandro Repici ${ }^{1,2^{* *}}$ \\ *these authors equally contributed to this work \\ **these authors shared the senior authorship \\ Affiliations: \\ 1. Humanitas Research Hospital, Digestive Endoscopy unit, Rozzano, Italy \\ 2. Humanitas University, Department of Biomedical Sciences, Rozzano, Italy \\ 3. Navarrabiomed Research Institute/ Public University of Navarra/IdiSNA, Endoscopy \\ Research Department, Pamplona. Spain. \\ 4. Dartmouth Geisel School of Medicine, Digestive Endoscopy unit, Hanover, New Hampshire, \\ United States \\ 5. Kansas City VA Medical Center, Gastroenterology and Hepatology, Kansas City, United \\ States \\ 6. Sano Hospital, Gastrointestinal Center and Institute of Minimally-invasive Endoscopic \\ Care, Kobe, Japan. \\ 7. Hospital del Mar, Gastroenterology Department, Barcelona. Spain. \\ 8. Indiana University School of Medicine, Digestive Endoscopy unit, Indianapolis, Indiana, \\ United States \\ 9. Nuovo Regina Margherita Hospital, Digestive Endoscopy Unit, Rome, Italy.
}

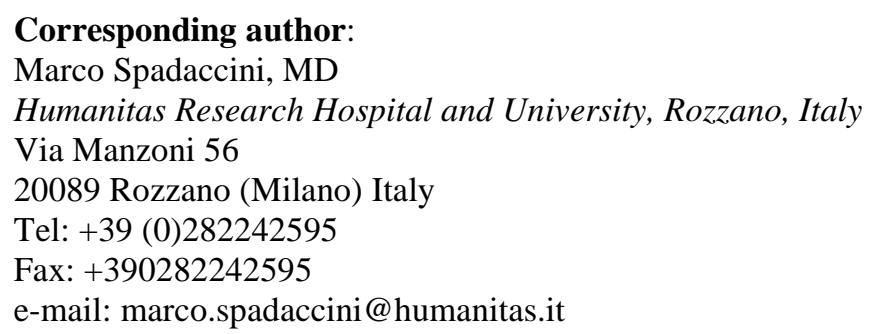

Grant support: none.

Disclosure: The authors disclose no potential conflicts of interest related to this topic.

This is the author's manuscript of the article published in final edited form as:

Spadaccini, M., Albéniz, E., Pohl, H., Maselli, R., Chandrasekar, V. T., Correale, L., ... \& Iwatate, M. (2020). Prophylactic Clipping After Colorectal Endoscopic Resection Prevents Bleeding of Large, Proximal Polyps: Meta-Analysis of Randomized Trials. Gastroenterology. https://doi.org/10.1053/j.gastro.2020.03.051 


\section{Author contributions:}

Marco Spadaccini: study concept and design, drafting of the manuscript, acquisition of data, analysis and interpretation of data.

Eduardo Albéniz: study concept and design, acquisition of data, analysis and interpretation of data. Heiko Pohl: study concept and design, acquisition of data, analysis and interpretation of data.

Roberta Maselli: study concept and design, acquisition of data, analysis and interpretation of data. Viveksandeep Thoguluva Chandrasekar: study concept and design, analysis and interpretation of data.

Loredana Correale: study concept and design, statistical analysis, analysis and interpretation of data.

Andrea Anderloni: study concept and design, analysis and interpretation of data.

Silvia Carrara: study concept and design, analysis and interpretation of data.

Alessandro Fugazza: study concept and design, analysis and interpretation of data.

Matteo Badalamenti: study concept and design, analysis and interpretation of data.

Mineo Iwatate: study concept and design, analysis and interpretation of data.

Giulio Antonelli: study concept and design, analysis and interpretation of data.

Mónica Enguita-Germán: study concept and design, analysis and interpretation of data.

Marco Antonio Álvarez: study concept and design, analysis and interpretation of data.

Prateek Sharma: study concept and design, drafting of the manuscript, analysis and interpretation of data.

Douglas K. Rex: study concept and design, analysis and interpretation of data.

Cesare Hassan: study concept and design, drafting of the manuscript, analysis and interpretation of data.

Alessandro Repici: study concept and design, drafting of the manuscript, analysis and interpretation of data.

\section{Acknowledgments}

The authors thank all the participants of the clinical trials for the transfer of the data of the included studies, without whose contribution this work could not have been carried out.

Eduardo Albéniz has been granted by "La Caixa/Caja Navarra" Foundation (ID 100010434; Project PR15/11100006) for the trial “Albéniz E, Álvarez MA, Espinós JC et al. Clip Closure After Resection of Large Colorectal Lesions With Substantial Risk of Bleeding. Gastroenterology. 2019 Nov;157(5):1213-1221.e4. doi: 10.1053/j.gastro.2019.07.037. Epub 2019 Jul 27.” 
Abbreviations:

- Colorectal Cancer (CRC)

- Post-polypectomy (delayed) bleeding (PPB)

- European Society of Gastrointestinal Endoscopy (ESGE)

- Randomized controlled trials (RCTs)

- Preferred Reporting Items for Systematic Reviews and Meta-Analyses (PRISMA)

- Intention-to-treat (ITT)

- Per-protocol (PP)

- Risk ratios (RR)

- Prediction interval (PI)

- Odds ratios (ORs) 


\section{Clipping vs not clipping in preventing Post-Polypectomy Bleeding}

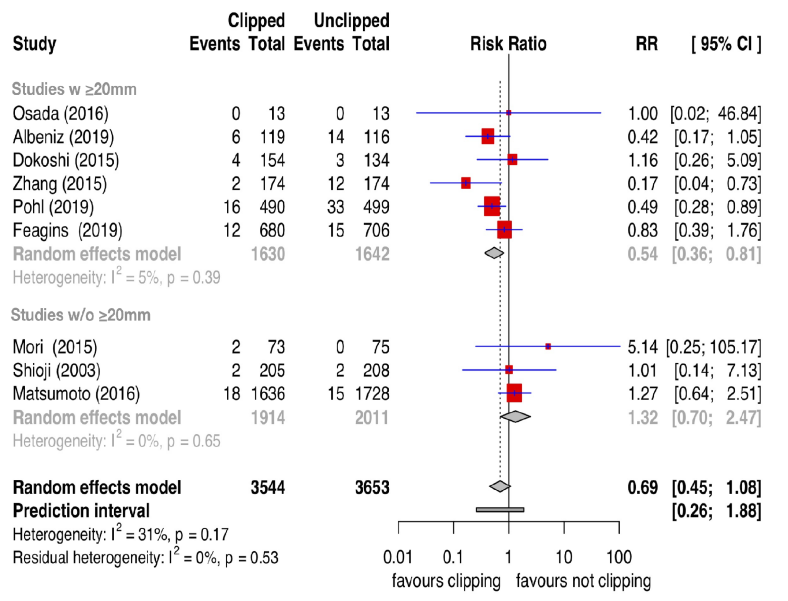

Sub-analysis of size according to location.

PPB risk: Clipping vs Not-Clipping Large and proximal polyps: $3.8 \%$ vs $10.0 \%$ Small and distal polyps: $2.2 \%$ vs $1.6 \%$ (ns)

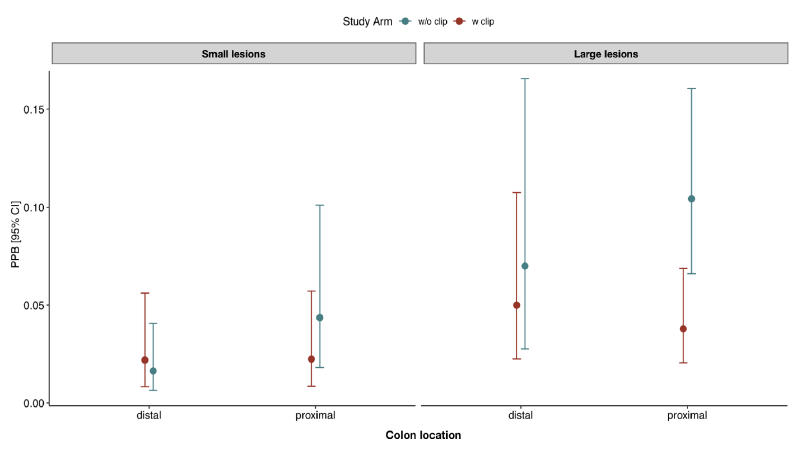

Clipping appeared to be beneficial after resection of large and proximal lesions 
Abstract:

Background \& Aims: The benefits of prophylactic clipping to prevent bleeding after polypectomy are unclear. We conducted an updated meta-analysis of randomized trials to assess the efficacy of clipping in preventing bleeding after polypectomy, overall and according to polyp size and location.

Methods: We searched the Medline/PubMed, EMBASE, and Scopus databases randomized trials that compared effects of clipping vs not clipping to prevent bleeding after polypectomy. We performed a random-effects meta-analysis to generate pooled relative risks (RRs) with 95\% CIs. Multilevel random-effects meta-regression analysis was used to combine data on bleeding after polypectomy and estimate associations between rates of bleeding and polyp characteristics.

Results: We analyzed data from 9 trials, comprising 7197 colorectal lesions $(22.5 \% 20 \mathrm{~mm}$ or larger, $49.2 \%$ with proximal location). Clipping, compared with no clipping, did not significantly reduce the overall risk of post-polypectomy bleeding (2.2\% with clipping vs $3.3 \%$ with no clipping; RR, 0.69; 95\% CI, 0.45-1.08; $P=.072$ ). Clipping significantly reduced risk of bleeding after removal of polyps that were $20 \mathrm{~mm}$ or larger (4.3\% had bleeding after clipping vs $7.6 \%$ had bleeding with no clipping; RR, $0.51 ; 95 \% \mathrm{CI}, 0.33-0.78 ; P=.020)$ or that were in a proximal location $(3.0 \%$ had bleeding after clipping vs $6.2 \%$ had bleeding with no clipping; RR, $0.53 ; 95 \%$ CI, $0.35-0.81 ; P<.001)$. In multilevel meta-regression analysis that adjusted for polyp size and location, prophylactic clipping was significantly associated with reduced risk of bleeding after removal of large proximal polyps (RR, 0.37 ; 95\% CI, $0.22-0.61 ; P=.021)$ but not small proximal lesions (RR, $0.88 ; 95 \%$ CI, $0.48-1.62 ; P=0.581)$.

Conclusions: In a meta-analysis of randomized trials, we found that routine use of prophylactic clipping does not reduce risk of post-polypectomy bleeding, overall. However, clipping appeared to reduce bleeding after removal of large (more than $20 \mathrm{~mm}$ ), proximal lesions.

Key words: comparison, colonoscopy, complication, PPB 


\section{BACKGROUND}

Colonoscopy and endoscopic resection of precancerous lesions significantly decreases the risk of Colorectal Cancer (CRC) incidence and death [1-3]. However, endoscopic procedures might result in adverse events, such as post-procedural pain, intra- or post-procedural bleeding, perforation and even death [4]. Post-procedural (delayed) bleeding (PPB) after polypectomy and endoscopic mucosal resection is the most common major adverse event, ranging from $1 \%$ to $6 \%$ [5,6]. Larger lesion size and proximal location are well-established risk factors for PPB [7,8]. PPB may require the need for hospitalization, blood transfusion, and further endoscopic or more invasive treatments, representing a risk for the patient and a burden to the health system.

Despite lack of high quality evidence, prophylactic clipping has been advocated as a technique to reduce the risk of PPB. For instance, the European Society of Gastrointestinal Endoscopy (ESGE) suggests that there may be a role for prophylactic clipping, and that this decision be based on patient risk factors [4]. However, this recommendation has been graded as weak since it is based on low quality evidence. Previous meta-analysis, mostly analyzing studies with small lesions $(<20 \mathrm{~mm})$ and at high risk of bias, reported no protective effect of prophylactic clipping for non-pedunculated lesions [9-11]. Recently, high-quality randomized controlled trials (RCTs) have been published, investigating the efficacy of prophylactic clipping primarily for lesions larger than $20 \mathrm{~mm}$. However, there is uncertainty on the overall efficacy of clipping and whether it is possible to identify sub-groups that may benefit from prophylactic clipping. This issue is clinically relevant considering the costs and technical complexity of clipping.

We performed a systematic review and meta-analysis of all available RCTs to clarify the role of prophylactic clipping in preventing post polypectomy bleeding following endoscopic resection of colorectal lesions. 


\section{METHODS}

The methods of our analysis and inclusion criteria were based on Preferred Reporting Items for Systematic Reviews and Meta-Analyses (PRISMA) recommendations [12]. Our systematic review protocol was registered with the International Prospective Register of Systematic Reviews (PROSPERO, www.crd.york.ac.uk/prospero/) on October 2019.

The following methods are reported in appendix 1: data sources and search strategy, the selection process, data extraction and the quality assessment.

\section{Inclusion and exclusion criteria}

For the purpose of our meta-analysis, we screened all clinical studies for the following inclusion criteria:

(I) Population: all adults undergoing endoscopic resection of colorectal lesions.

(II) Intervention: post-polypectomy prophylactic closure of mucosal defects with hemoclips.

(III) Comparison: no prophylactic clipping post-polypectomy.

(IV) Outcome: risk of delayed post-polypectomy bleeding.

(V) Study design: only randomized controlled trials were considered.

Exclusion criteria were as follows:

(I) Essential information not available;

(II) Studies not published as full text article;

(III) Studies not published in the English language;

(IV) Studies considering as comparator any intervention strategy for post procedural bleeding prophylaxis (i.e. cauterization of post-procedural ulcer floor by argon plasma coagulation, injective strategies, use of topical hemostatic agents, etc).

(V) studies including less than 10 patients in each group

\section{Study end-points}

The primary aim of this study was to assess the efficacy of endoscopic clipping for the prevention of PPB. We included all patients randomly assigned to the clipping group in the intention-to-treat (ITT) analysis. When both sets of data were provided, values from ITT were preferred to perprotocol (PP). A per-protocol (PP) analysis was also conducted, including only those patients who underwent a complete closure of the mucosal defect. PPB was defined as any post procedural clinically evident hematochezia that required medical intervention (hospitalization, blood transfusion, repeated colonoscopy, angiography or surgery) or caused a more than $2 \mathrm{~g} / \mathrm{dL}$ decrease in the blood hemoglobin concentration. 
The secondary aim of the study was to determine the effect of risk factors (patient and lesion) on the risk of PPB with and without clipping. The risk factors taken into account were: patient age and gender, use of antiplatelet/anticoagulant therapy, as well as lesion characteristics such as the polyp size; morphology and location (proximal), and histology (serrated and adenomatous). Lesions $\geq 20 \mathrm{~mm}$ were defined as 'large' and morphology was described according to the Paris classification [13]. Lesion location was defined as per the reporting in the studies. An additional secondary aim was to assess the efficacy of endoscopic clipping for the prevention of other post-procedural adverse events such as perforation.

\section{Statistical Analysis}

All statistical analyses were conducted with the R program (version 3.5.1, 2018-07-02) [14]. In particular, we used the meta [15] and metafor [16] libraries in $\mathrm{R}$ to conduct the meta-analysis and meta-regression analysis. All tests are two tailed. For all tests, a probability level less than .05 was considered significant. Study characteristics were summarized using descriptive statistics. Risk ratios (RR) and 95\% CIs were estimated with the Mantel-Haenszel (fixed-effects model) and the DerSimonian-Laird (random-effects model) methods. The summary effect sizes from randomeffects meta-analysis (assumption that the effects estimated in the different studies were not identical) were calculated. We assessed statistical heterogeneity between studies by visual inspection of forest plots and by the $\mathrm{I}^{2}$ and $\chi 2$ statistics for heterogeneity. $\mathrm{I}^{2}$-values of $0-30 \%, 30$ $60 \%, 50-90 \%$ and $75-100 \%$ were classified as low, moderate, substantial and considerable heterogeneity, respectively. We also calculated the $95 \% \mathrm{CI}$ for pooled estimates, as well as the prediction interval (PI) [17].

Sensitivity analyses were performed to assess the stability of the results, namely, a single study in this meta-analysis was omitted one at a time to assess the influence of the individual study to the pooled RR [18]. Visual inspection of funnel plot asymmetry was conducted along with the Egger's weighted regression method to assess publication bias $(\mathrm{P}<0.05$ was considered statistically significant).

\section{Meta-Regression Analysis of relative risk estimates and subgroup analyses}

We conducted a meta-regression analysis to investigate the impact of various risk factors on the study estimates of relative risk. The natural logarithm of the risk ratio was the dependent variable, and study level characteristics (e.g., number of participants, mean age, percentage of males, the percentage of proximal polyps, the percentage of large polyps) were entered as explanatory factors. As the first step, we performed univariate regression analyses for each factor. All significant factors 
(at a significance level of $\mathrm{p}<0.10$ ) were then included in a multivariable regression model. The estimated coefficients of the regression model corresponded to differences in the log risk ratios for one unit of difference in the explanatory factor (continuous variable) or for each category relative to the baseline category (for categorical explanatory variables). Of note, input percentages (e.g., the percentage of proximal polyps) were analyzed as continuous variables, expressed originally as decimal fractions. The percentages were multiplied by 10 before entering in the regression model. Therefore, a change of 1 unit on the scaled variables corresponded to a change of $0.10(10 \%)$ in the original variables. Subgroup analyses were also performed according to the polyp location (proximal vs. distal colon) and size (large vs. small polyps).

Multilevel (random-effects) model: meta-analysis of rates of PPB with clipping versus no clipping As a subsequent step, we performed a multilevel regression analysis to estimate the rates of PPB associated with clipping versus no clipping. The outcome measure in this analysis was the proportion of PPB transformed via logits. Since the studies included in the analysis reported multiple outcome measures, we used a multilevel meta-analysis method to combine data, with random effects at both the study level and at the outcome level (see Appendix 1). The multilevel model was extended by including predictor variables (i.e., study group, prevalence of large lesions and proximal colon location) in an attempt to determine variables that moderate the effect. In this model, predictor variables were aggregated at the study-arm level. We also considered appropriate interactions between these variables. Data were presented as odds ratios (ORs) and 95\% CIs. This analysis was an indirect way to deal with aspects such as the possibility of effect modification by polyp characteristics, and to examine for decreasing bleeding risk with clipping vs. not clipping. 


\section{RESULTS}

Study characteristics and quality

The initial literature search resulted in 1112 articles (Figure 1). A total of 9 trials were included in the final analysis [19-27]. Study characteristics are shown in Table 1. Studies were published between 2003 and 2019 in USA (n=3), Europe $(n=1)$ and Asia $(n=5)$. Five studies involved multiple centers, while 4 studies were single-center experiences. The objective assessment of the risk of bias is reported in Supplemental Table 1 (Appendix 2).

The total number of participants included in the intention-to-treat analysis was 4557 (2288 in the clipping and 2,269 in the control group), and the individual study sample size ranged from 26 to 1,499 patients. Mean patient age ranged from 60.5 to 72.7 years. A total of 7197 colorectal lesions were analyzed (3544 clip and 3653 control group). The percentage of proximal polyps ranged from $25 \%$ to $92 \%$ with the mean percentage at $49.2 \%$. The mean size of polyps ranged from $7.8 \mathrm{~mm}$ to $37.3 \mathrm{~mm}$ with an average polyp size of $18.6 \mathrm{~mm}$. Of the analyzed studies, 3 included only patients with polyps $>20 \mathrm{~mm} ; 3$ with patients having polyps of any size (mean percentage of lesions $\geq 20$ $\mathrm{mm}, 19.4 \%$ ), whereas the remaining 3 studies included only lesions $<20 \mathrm{~mm}$ in size.

\section{Effect of clipping on PPB risk}

Based on data reported by all 9 trials, the estimates of PPB risk between the control and clip groups were $3.3 \%$ (95\% CI:1.9-5.7\%) and 2.2\% (95\% CI:1.2-3.9\%) (multilevel random-effect model accounting for the underlying heterogeneity between and within trials), respectively (Appendix 3. Supplemental Figure 1). No significant difference between the 2 groups was noted for the risk of PPB when a random-effects model was applied $(R R=0.69,95 \% \mathrm{CI}: 0.45-1.08, \mathrm{p}=0.072$, Figure 2). Moderate heterogeneity among the studies existed $\left(\mathrm{I}^{2}=31 \%, \mathrm{p}=0.170\right)$, and the likelihood of publication bias was low ( $\mathrm{p}=0.42$ ) (Appendix 3. Supplemental Figure 2). The results of the metaanalysis did not change substantially when data from "per-protocol" analysis were combined (Appendix 3. Supplemental Figure 3). The results of the "Leave-One-Out" sensitivity analysis are reported in Appendix 2. Supplemental Table 2. Only one study that evaluated patients with lesions $<20 \mathrm{~mm}$ was determined to have a substantial influence on the overall effect size [23]. After removing this trial (in a sensitivity analysis) the heterogeneity was significantly reduced $\left(\mathrm{I}^{2}=8.2 \%\right)$ and the pooled (random-effects) RR was 0.58 [0.39; 0.88]. To further investigate the impact of study level characteristics on RR estimates, we performed a meta-regression analysis (Table 2). The analysis showed that use of prophylactic clipping was associated with a significant 
reduction in PPB as the percentage of large lesions in the study population increased. The metaregression coefficient for the percentage of large $(\geq 20 \mathrm{~mm})$ lesions was 0.92 (95\% CI: 0.85-0.98), indicating that for every $10 \%$ increase in the percentage of large lesions, the RR of PPB decreased by $8 \%$ (95\% CI:2-15\%) if prophylactic clipping was utilized (Appendix 3. Supplemental Figure 4). This finding was remarkably robust in the multilevel multivariate analysis (Appendix 2. Supplementary Table 3).

\section{Effect of clipping on PPB risk according to polyp size}

A sub-group analysis by polyp size (large versus small polyps) confirmed the above metaregression result (Figure 3). A beneficial effect of clipping was determined among studies including $\geq 20 \mathrm{~mm}$ polyps ( $\mathrm{RR}=0.51 ; 95 \% \mathrm{CI}: 0.33-0.78$ ), while among those with $<20 \mathrm{~mm}$ polyps, there was no significant benefit ( $\mathrm{RR}=1.04$; 95\% CI:0.60-1.79). According to multilevel randomeffects meta-regression analysis, the estimated rates of PPB among $\geq 20 \mathrm{~mm}$ and $<20 \mathrm{~mm}$ lesions were $7.6 \%$ (95\% CI:4.9-11.5\%) and 1.8\% (95\% CI:1.1-2.9\%), respectively, in the control group compared to $4.3 \%$ (95\% CI:2.5-7.1\%) and $1.4 \%$ (95\% CI:0.9-2.4\%), respectively, in the prophylactic clipping group (Appendix 2. Supplemental Table 4 Appendix 3. Supplemental

Figure 5). Again, the multilevel model indicated showed a protective effect of clipping for large polyps that remained significantly after adjusting for the prevalence of proximal polyps (OR, 0.53 ; 95\% CI:0.31-0.90).

Effect of clipping on PPB risk based on polyp location with sub-analysis by size.

Seven trials with available data on proximal/distal lesions (1618/1648 clipped and 1650/1720 control groups) were included in this analysis. Figure 4 graphs the risk ratios and 95\% CIs from the individual trials and the pooled results. Among proximally located lesions, there was a significant association between use of prophylactic clipping and risk of PPB (RR=0.53; 95\% CI:0.35-0.81). However, among distally located lesions there was no significant difference between the 2 groups and risk of $\mathrm{PPB}(\mathrm{RR}=1.01 ; 95 \% \mathrm{CI}$ : 0.43-2.37). This association was corroborated by both sensitivity analysis among studies defining proximal lesions as those located proximal to the splenic flexure (including transverse colon), and those defining proximal lesions as in the cecum, ascending colon or hepatic flexure (Appendix 3. Supplemental Figure 6 and 7). According to a multilevel random-effects meta-regression analysis, the estimated rates of PPB in the distal and proximal colon were $2.7 \%$ (95\% CI:1.3-5.4\%; PI:0.5-12.3\%) and 6.2\% (95\% CI:3.4-11.1\%; PI:1.3-24.3\%), respectively, in the control group compared to 3.3\% (95\% CI:1.6-6.5\%; PI:0.7-14.6\%) and 3.0\% (95\% CI:1.5-5.7\%; PI:0.6-13.2\%), respectively, in the clip group (Appendix 3. Supplementary 
Figure 8). The above model showed a protective effect of clipping for proximally located polyps (clipped proximal vs. unclipped proximal polyps, OR, 0.46; 95\% CI:0.24-0.88) (Appendix 3 Table $5)$.

After adjusting for the prevalence of large lesions in the multilevel model, the benefit of clipping in reducing PPB was significant only for large proximal lesions (clipped versus unclipped polyps, OR, 0.37; 95\% CI:0.22-0.61; $\mathrm{p}=0.021$ ), but not for small proximal lesions (clipped versus unclipped polyps, OR, 0.88; 95\% CI:0.48-1.62; p=0.581). This finding was remarkably robust in sub-group and sensitivity analyses (Figure 5 and Appendix 3 Supplementary Figure 9). Clipping was also not beneficial for large distal lesions (RR:0.70; 95\% CI:0.22-2.27), although this outcome mainly depended by the lack of benefit in only one large series (Appendix 3. Supplementary Figure 10), and for small distal lesions (RR:1.34; 95\% CI:0.42-4.35; Figure 5).

\section{Perforations.}

Data on perforation were available in 6 studies. In total, 14 perforation events were reported (6/1074, $0.56 \%$ in the clip and 8/1085, $0.74 \%$ in control group) with a RR of 0.70; 95\% CI:0.251.91; $\mathrm{p}=0.480 ; \mathrm{I} 2=0.0 \%$ ), indicating no significant differences between groups.

\section{Additional analysis}

The quality of evidence was assessed by applying the GRADE methodology. The level of evidence for RCTs was downgraded due to low-moderate quality of the included RCTs (assessed by Cochrane risk bias tool for randomized studies) and the inconsistency owing to heterogeneity among patients (i.e. different indications to resection in term of lesion size or location). Details can be found in Appendix 2. Supplemental Table 6.

Additional technical features such as types of clips used and electrosurgical unit characteristics are detailed in Appendix 2. Supplemental Table 7. 


\section{DISCUSSION}

According to our meta-analysis, routine practice of endoscopic clipping as a prophylactic intervention does not reduce the risk of post-polypectomy bleeding. However, clipping was effective in reducing the risk of PPB by nearly $50 \%$ for large lesions ( $\geq 20 \mathrm{~mm}$ ). If such lesions do not undergo endoscopic clipping, there was 4-fold increase in the baseline risk of PPB as compared with those $<20 \mathrm{~mm}$. Such benefit appeared to be limited to large lesions located in the proximal colon.

The results of our analysis are relevant for several reasons. Meta-analysis of randomized trials is considered as the strongest evidence for clinical recommendations. The lack of efficacy of prophylactic clipping after any polypectomy was confirmed by our results showing no significant difference in PPB risk between the 2 groups (clip vs control group). This was further confirmed by the 'leave-one-analysis' - i.e. clipping became significantly effective when excluding this series as this was the largest series on small lesions. This inference is a distinctive advantage of our analysis, as the previous systematic reviews were not powered enough to perform it [9-11, 30-32].

Our analysis showed the clinical relevance of two main factors: polyp size and location, on both the absolute risk of PPB and the relative efficacy of clipping, as well as their hierarchical interaction. Our adjusted estimates attributed a nearly 2-fold increase - from $4.3 \%$ to $7.6 \%$ - in the risk of PPB for lesions $\geq 20 \mathrm{~mm}$. This finding was supported by two additional results. First, the PPB risk estimate proportionally increased as the percentage of $\geq 20 \mathrm{~mm}$ increased in the included studies. Secondly, such cut-off size was the only significant risk factor associated at metaregression with PPB risk.

While showing an increase in the PPB risk according to size, our data also showed a clear reduction in PPB risk with clipping. A 50\% reduction in PPB for those with clipped $\geq 20 \mathrm{~mm}$ lesions directly translated to a NNT of 23 for lesions to be clipped in order to prevent one additional bleeding. A recent US-based study showed significant cost-savings when adopting such a cut-off [33].

Regarding location, our data support proximal location as possible risk factor for PPB risk and clipping efficacy. In the control group we observed a 2-fold increase in the risk for PPB for polyps located in the distal versus the proximal colon - from $2.7 \%$ to $6.2 \%$ respectively. Regarding the interaction between size and location, size $\geq 20 \mathrm{~mm}$ appeared to be the primary determinant of PPB risk. Thus, the benefit of clipping was clear in large proximal lesions, while it was absent for small lesions, even when they were located in the proximal colon. On the other hand, the risk of 
PPB and clipping efficacy was somewhat intermediate - albeit not statistically significant - for large and distal lesions. This was mainly attributed to the lack of the effect of clipping in a large study on $\geq 20 \mathrm{~mm}$ lesions [26]. However, this was not confirmed by other studies generating some uncertainty on the benefit of prophylactic clipping for large distal lesions. Thus, the decision for large and distal lesions should be tailored, especially taking into consideration other patient- and polyp-risk factors for PPB, such as the use of anti-thrombotic agent or intra-procedural bleeding. The studies included in our analysis did not reveal significant heterogeneity nor publication bias. This indicates that the effect is homogeneous across the different series, suggesting generalizability and reproducibility of the results. Of note, the only study that contributed to the slight heterogeneity on our primary end-point [23] included only small polyps, suggesting that such size inclusion criteria could explain the slight degree of heterogeneity, as confirmed by subsequent metaregression and subgroup results. In addition, the observation that the effect is orientated towards clipping efficacy in the vast majority of the cases strengthens the robustness of our observation.

Our data pair with recent cost-effectiveness analysis (using Medicare cost data and CMS billing codes) focusing on the impact of adoption of routine prophylactic clipping in practice from a payer perspective, considering relevant patient- and polyp-specific factors [33]. Considering that clips are expensive and their placement might be technically demanding, prophylactic clipping tailored for a subgroup of higher risk lesions/patients would decrease in parallel both adverse events and costs. Our data support the use of clipping for any large proximal lesion, excluding its use for those $<20 \mathrm{~mm}$ and those located in the distal colon. On the other hand, the choice for large distal ones is likely to be less effective, and should be individualized according to also patient characteristics [34].

There are the limitations to our study. First of all, the paucity of data about patient's comorbidities and the management of antithrombotic therapies prior to endoscopic resection in many of the included studies limited our ability to infer on this relevant topic. Thus, high quality RCTs are needed to determine whether prophylactic clips should be suggested after resecting small $(<20 \mathrm{~mm})$ and distal lesions in patients on antithrombotic therapies. Secondly, some of the included studies were of low to moderate quality, limiting the quality of our recommendations. Furthermore, study limitations such as lack of blinding of outcome assessors could almost be considered as intrinsic of RCTs evaluating endoscopic procedures, yet remaining the best possible evidence. Also, several patients included in the analysis underwent multiple resections. In case of bleeding, it is sometimes difficult to determine which polypectomy site was bleeding in patients who did not undergo colonoscopy. Further, even in cases requiring endoscopy the bleeding site may remain 
uncertain. Last, we were not able to stratify data according to technical variables that might affect the risk of bleeding (and the effect of clipping) such as hemoclips or electrosurgical unit characteristics (Supplemental Table 7).

In conclusion, the results of our meta-analysis of RCTs do not support the routine use of prophylactic clipping for the prevention of PPB. However, clipping appeared to be beneficial in patients with large (>20 mm) and proximal lesions. 


\section{References}

1. Zauber AG, Winawer SJ, O'Brien MJ, Lansdorp-Vogelaar I, van Ballegooijen M, Hankey BF, Shi W, Bond JH, Schapiro M, Panish JF, Stewart ET, Waye JD. Colonoscopic polypectomy and long-term prevention of colorectal-cancer deaths. $\mathrm{N}$ Engl J Med 2012; 366: 687-696 [PMID: 22356322 DOI: 10.1056/NEJMoa1100370].

2. Zorzi M, Senore C, Da Re F, et al. Detection rate and predictive factors of sessile serrated polyps in an organised colorectal cancer screening programme with immunochemical faecal occult blood test: The EQuIPE study (Evaluating Quality Indicators of the Performance of Endoscopy). Gut 2017;66(7):1233-40.

3. Nishihara R, Wu K, Lochhead P, et al. Long-term colorectal-cancer incidence and mortality after lower endoscopy. N Engl J Med 2013;369(12):1095-105.

4. Monika Ferlitsch, Alan Moss, Cesare Hassan, Pradeep Bhandari, Jean-Marc Dumonceau, Gregorios Paspatis, Rodrigo Jover, Cord Langner, Maxime Bronzwaer, Kumanan Nalankilli, Paul Fockens, Rawi Hazzan, Ian M. Gralnek, Michael Gschwantler, Elisabeth Waldmann, Philip Jeschek, Daniela Penz, Denis Heresbach, Leon Moons, Arnaud Lemmers, Konstantina Paraskeva, Juergen Pohl, Thierry Ponchon, Jaroslaw Regula, Alessandro Repici, Matthew D. Rutter, Nicholas G. Burgess, Michael J. Bourke. Colorectal polypectomy and endoscopic mucosal resection (EMR): European Society of Gastrointestinal Endoscopy (ESGE) Clinical Guideline. Endoscopy 2017; 49(03): 270-297 DOI: https://dx.doi.org/10.1055/s-0043-102569

5. C.W. Ko, S. Riffle, L. Michaels et al., "Serious complications within 30 days of screening and surveillance colonoscopy are uncommon," Clinical Gastroenterology and Hepatology, vol. 8, no. 2, pp. 166-173, 2010.

6. S.W. Rathgaber and T. M.Wick, "Colonoscopy completion and complication rates in a community gastroenterology practice," Gastrointestinal Endoscopy, vol. 64, no. 4, pp. 556-562, 2006.

7. Bahin FF, Rasouli KN, Byth K, et al. Prediction of clinically significant bleeding following wide-field endoscopic resection of large sessile and laterally spreading colorectal lesions: A clinical risk score. Am J Gastroenterol 2016;111(8):1115-22.

8. Veeravich Jaruvongvanich, Narut Prasitlumkum, Buravej Assavapongpaiboon, Sakolwan Suchartlikitwong, Anawin Sanguankeo, Sikarin Upala Risk factors for delayed colonic post-polypectomy bleeding: a systematic review and meta-analysis Int J Colorectal Dis (2017) 32:1399-1406 DOI 10.1007/s00384-017-2870-0.

9. Park CH, Jung YS, Nam E, et al. Comparison of efficacy of prophylactic endoscopic therapies for postpolypectomy bleeding in the colorectum: A systematic review and network meta-analysis. Am J Gastroenterol 2016;14(8):1140-7.

10. Boumitri C, Mir FA, Ashraf I, et al. Prophylactic clipping and post-polypectomy bleeding: A meta-analysis and systematic review. Ann Gastroenterol 2016;29(4):502-8.

11. Nishizawa T, Suzuki H, Goto O, et al. Effect of prophylactic clipping in colorectal endoscopic resection: A meta-analysis of randomized controlled studies. United European Gastroenterol J 2017;5(6):859-67

12. Shamseer L, Moher D, Clarke M, et al. Preferred reporting items for systematic review and meta-analysis protocols (PRISMA-P) 2015: elaboration and explanation. BMJ 2015;g7647:350

13. The Paris endoscopic classification of superficial neoplastic lesions: esophagus, stomach, and colon: November 30 to December 1, 2002. Gastrointest Endosc. 2003 Dec;58(6 Suppl):S3-43.

14. R Development Core Team. R: a language and environment for statistical computing. Vienna,Austria: R Foundation for Statistical Computing,2016.

15. Schwarzer G. meta: An R package for meta-analysis. R News 2007; 7:40-45.

16. Viechtbauer W. Conducting meta-analyses in R with the metafor package. J Stat Softw 2010; 36:1-48.

17. Higgins J. The Cochrane Collaboration, version 5.0.2. Available at: http://www.cochrane-handbook.org. Updated September 2009.

18. Viechtbauer W, Cheung MW. Outlier and influence diagnostics for meta-analysis. Res Synth Methods 2010; $1: 112-125$

19. Shioji K, Suzuki Y, Kobayashi M, et al. Prophylactic clip application does not decrease delayed bleeding after colonoscopic polypectomy. Gastrointest Endosc. 2003 May;57(6):691-4.

20. Dokoshi T, Fujiya M, Tanaka K et al. A randomized study on the effectiveness of prophylactic clipping during endoscopic resection of colon polyps for the prevention of delayed bleeding. Biomed Res Int. 2015;2015:490272. doi: 10.1155/2015/490272. Epub 2015 Feb 3.

21. Mori H, Kobara H, Nishiyama $\mathrm{N}$ et al. Simple and reliable treatment for post-EMR artificial ulcer floor with snare cauterization for 10 - to $20-\mathrm{mm}$ colorectal polyps: a randomized prospective study (with video). Surg 
Endosc. 2015 Sep;29(9):2818-24. doi: 10.1007/s00464-014-3983-y. Epub 2014 Dec 6.

22. Zhang QS, Han B, Xu JH et al. Clip closure of defect after endoscopic resection in patients with larger colorectal tumors decreased the adverse events. Gastrointest Endosc. 2015 Nov;82(5):904-9. doi: 10.1016/j.gie.2015.04.005. Epub 2015 May 12.

23. Matsumoto $\mathrm{M}$, Kato $\mathrm{M}$, Oba $\mathrm{K}$ et al. Multicenter randomized controlled study to assess the effect of prophylactic clipping on post-polypectomy delayed bleeding. Dig Endosc. 2016 Jul;28(5):570-6. doi: 10.1111/den.12661. Epub 2016 May 25.

24. Osada T, Sakamoto N, Ritsuno H et al Closure with clips to accelerate healing of mucosal defects caused by colorectal endoscopic submucosal dissection. Surg Endosc. 2016 Oct;30(10):4438-44. doi: 10.1007/s00464016-4763-7. Epub 2016 Feb 19.

25. Albéniz E, Álvarez MA, Espinós JC et al. Clip Closure After Resection of Large Colorectal Lesions With Substantial Risk of Bleeding. Gastroenterology. 2019 Nov;157(5):1213-1221.e4. doi: 10.1053/j.gastro.2019.07.037. Epub 2019 Jul 27.

26. Pohl H, Grimm IS, Moyer MT et al Clip Closure Prevents Bleeding After Endoscopic Resection of Large Colon Polyps in a Randomized Trial. Gastroenterology. 2019 Oct;157(4):977-984.e3. doi: 10.1053/j.gastro.2019.03.019. Epub 2019 Mar 15.

27. Feagins LA, Smith AD, Kim D et al. Efficacy of Prophylactic Hemoclips in Prevention of Delayed PostPolypectomy Bleeding in Patients With Large Colonic Polyps. Gastroenterology. 2019 Oct;157(4):967-976.e1. doi: 10.1053/j.gastro.2019.05.003. Epub 2019 May 31.

28. Rex DK. Prophylactic Clip Closure Clarified: The Question Is Not Whether to Clip, But When. Gastroenterology. 2019 Nov;157(5):1190-1192. doi: 10.1053/j.gastro.2019.08.036. Epub 2019 Sep 4.

29. Thoguluva Chandrasekar V, Spadaccini M, Aziz M et al. Cold snare endoscopic resection of nonpedunculated colorectal polyps larger than $10 \mathrm{~mm}$ : a systematic review and pooled-analysis. Gastrointest Endosc. 2019 May;89(5):929-936.e3. doi: 10.1016/j.gie.2018.12.022. Epub 2019 Jan 9.

30. Forbes N, Frehlich L, James MT, Hilsden RJ, Kaplan GG, Wilson TA, Lorenzetti DL, Tate DJ, Bourke MJ, Heitman SJ. Routine Prophylactic Endoscopic Clipping Is Not Efficacious in the Prevention of Delayed PostPolypectomy Bleeding: A Systematic Review and Meta-Analysis of Randomized Controlled Trials. J Can Assoc Gastroenterol. 2019 Aug;2(3):105-117. doi: 10.1093/jcag/gwy033.

31. Ayoub F, Westerveld DR, Forde JJ, Forsmark CE, Draganov PV, Yang D. Effect of prophylactic clip placement following endoscopic mucosal resection of large colorectal lesions on delayed polypectomy bleeding: A metaanalysis. World J Gastroenterol. 2019 May 14;25(18):2251-2263. doi: 10.3748/wjg.v25.i18.2251.

32. Mangira D, Ket SN, Majeed A, Gibson PR, Brown G. Postpolypectomy prophylactic clip closure for the prevention of delayed postpolypectomy bleeding: A systematic review. JGH Open. 2018 Mar 25;2(3):105-110. doi: 10.1002/jgh3.12047. eCollection 2018 Jun. Review

33. Shah ED, Pohl H, Rex DK et al. Routine Prophylactic Clip Closure is Cost Saving After Endoscopic Resection of Large Colon Polyps in a Medicare Population: Budget impact analysis: clip closure after resecting large colon polyps. Gastroenterology. 2019 Nov 15. pii: S0016-5085(19)41561-8. doi: 10.1053/j.gastro.2019.11.015. [Epub ahead of print].

34. Albéniz E, Gimeno-García AZ, Fraile M, et al Clinical validation of risk scoring systems to predict risk of delayed bleeding after EMR of large colorectal lesions. Gastrointest Endosc. 2019 Oct 23. pii: S00165107(19)32382-X. doi: 10.1016/j.gie.2019.10.013. [Epub ahead of print]. 


\section{Figure caption}

Figure 1. PRISMA flow diagram. RCTs: randomized controlled trials

Figure 2. Forest plot comparing clipping vs. not clipping arm. The relative risk of developing a post(delayed) polypectomy bleeding (PPB) event for polyps clipped or unclipped is displayed. The line-of-noeffect (vertical line) separates outcomes that favor clipping and not clipping. The squared red boxes represent the point estimates and the horizontal lines represent the associated $95 \%$ confidence intervals for each study. The area of each square is proportional to the study's weight in the meta-analysis. Overlapping confidence intervals of the individual studies and an $\mathrm{I}^{2}$ value of $31 \%$ with a non-significant p-value (0.17) indicates homogeneity of the studies. Studies were separated according to size criterion for polyp inclusion: studies including large lesions in their datasets (i.e., with, w lesions $\geq 20 \mathrm{~mm}$ ) and those including only lesions $<20 \mathrm{~mm}$ (i.e., without, w/o $\geq 20 \mathrm{~mm}$ ).

Figure 3 - Subgroup analysis of relative risk of developing post-polypectomy (delayed) bleeding events (PPB) with and without clipping for large polyps versus small polyps. For each subgroup, the relative risk of developing PPB for polyps clipped or unclipped is displayed. The line-of-no-effect (vertical line) separates outcomes that favor clipping and not clipping. The squared red boxes represent the point estimates and the horizontal lines represent the associated $95 \%$ confidence intervals for each study. The area of each square is proportional to the study's weight in the meta-analysis. Overlapping confidence intervals of the individual studies and $\mathrm{I}^{2}$ values with non-significant p-values indicates homogeneity of the studies.

Figure 4 - Subgroup analysis comparing clipping vs. not clipping arm for successful control of postpolypectomy (delayed) bleeding events (PPB) for distally and proximally located lesions. For each subgroup, the relative risk of developing a PPB for polyps clipped or unclipped is displayed. The line-of-no-effect (vertical line) separates outcomes that favor clipping and not clipping. The squared red boxes represent the point estimates and the horizontal lines represent the associated $95 \%$ confidence intervals for each study. The area of each square is proportional to the study's weight in the meta-analysis. Overlapping confidence intervals of the individual studies and a $\mathrm{I}^{2}$ value with a non-significant $\mathrm{p}$-value indicates homogeneity of the studies.

Figure 5 - Sub-analysis of size according to location. In this analysis, results from the studies were analyzed according two subgroups: studies including more than 50\% of large lesions in their analysis sets were considered "large" polyps, the others "small" polyps. The PPB risks for clipped and unclipped large and proximal polyps were 3.8\% (95\% CI:2.1-6.9\%) and 10.0\% (95\% CI:6.6-16.7\%) (RR, 0.34; 95\% CI:0.190.65), while PPB risks for small and proximal polyps were $2.2 \%$ (95\% CI:0.9-5.7\%) and $4.3 \%$ (95\% CI:1.1$10.1 \%$ ), respectively, (RR. 0.50; 95\% CI:0.16-1.57). The corresponding features for clipped and unclipped large and distal polyps were 5.0\% (95\% CI:2.2-10.7\%) and 7.0\% (2.8-16.6\%), respectively, (RR:0.70; 95\% CI:0.22-2.27), while PPB risks for small and distal polyps were 2.2\% (95\% CI:0.8-5.6\%) and 1.6\% (95\% CI:0.7-4.1\%), respectively (RR:1.34; 95\% CI:0.42-4.35). 
Table 1 - Study characteristics. NA: Not available; * standardized methods to measure polyp size were used

\begin{tabular}{|c|c|c|c|c|c|c|c|c|c|c|}
\hline Trial & Country & $\begin{array}{c}\text { Randomization } \\
\text { Level } \\
\text { (patients/polyps) }\end{array}$ & $\begin{array}{c}\text { Randomization } \\
\text { Time } \\
\text { (pre/post } \\
\text { resection) }\end{array}$ & $\begin{array}{l}\text { Patients } \\
\text { (clipped/ } \\
\text { unclipped) }\end{array}$ & $\begin{array}{c}\text { Male } \\
\text { (clipped/ } \\
\text { unclipped) }\end{array}$ & $\begin{array}{c}\text { Mean Age } \\
\text { (clipped/ } \\
\text { unclipped), years }\end{array}$ & $\begin{array}{c}\text { Polyps } \\
\text { (clipped/ } \\
\text { unclipped) }\end{array}$ & $\begin{array}{l}\text { Inclusion } \\
\text { criteria for } \\
\text { polyp size }\end{array}$ & $\begin{array}{l}\text { \# of large } \\
\text { lesions } \\
\text { (clipped/ } \\
\text { unclipped) }\end{array}$ & $\begin{array}{c}\text { \# of } \\
\text { proximal } \\
\text { lesions } \\
\text { (clipped/ } \\
\text { unclipped) }\end{array}$ \\
\hline $\begin{array}{r}\text { Albeniz }^{25} \\
\text { (2019) }\end{array}$ & Spain & Patients & Post & $\begin{array}{c}235 \\
(119 / 116)\end{array}$ & $\begin{array}{c}158 \\
(77 / 81)\end{array}$ & $\begin{array}{c}71.9 \\
(72.7 / 71.1)\end{array}$ & $\begin{array}{c}235 \\
(119 / 116)\end{array}$ & $\geq 20 \mathrm{~mm}^{*}$ & $\begin{array}{c}235 \\
(119 / 116)\end{array}$ & $\begin{array}{c}213 \\
(109 / 104)\end{array}$ \\
\hline $\begin{array}{c}\text { Dokoshi }^{20} \\
\text { (2015) }\end{array}$ & Japan & Patients & Pre & $\begin{array}{c}157 \\
(89 / 68)\end{array}$ & NA & $\begin{array}{c}67.4 \\
(67.1 / 67.8)\end{array}$ & $\begin{array}{c}288 \\
(154 / 134)\end{array}$ & $\begin{array}{l}\text { polyps of any } \\
\text { size } \\
(5 \%, \geq 20 \mathrm{~mm})\end{array}$ & $\begin{array}{c}14 \\
(8 / 6)\end{array}$ & $\begin{array}{c}74 \\
(40 / 34)\end{array}$ \\
\hline $\begin{array}{c}\text { Feagins }^{27} \\
(2019)\end{array}$ & US & Patients & Post & $\begin{array}{c}1050 \\
(530 / 520)\end{array}$ & $\begin{array}{c}1015 \\
(516 / 499)\end{array}$ & $\begin{array}{c}64.25 \\
(64.5 / 64)\end{array}$ & $\begin{array}{c}1386 \\
(680 / 706)\end{array}$ & $\begin{array}{l}\text { polyps of any } \\
\text { size * } \\
(39 \% \geq 20 \mathrm{~mm})\end{array}$ & $\begin{array}{c}222 \\
(101 / 121)\end{array}$ & $\begin{array}{c}536 \\
(261 / 275)\end{array}$ \\
\hline $\begin{array}{l}\text { Matsumoto }^{23} \\
\quad(2016)\end{array}$ & Japan & Patients & Pre & $\begin{array}{c}1499 \\
(752 / 747)\end{array}$ & $\begin{array}{c}1047 \\
(534 / 513)\end{array}$ & $\begin{array}{c}60.75 \\
(60.5 / 61)\end{array}$ & $\begin{array}{c}3364 \\
(1636 / 1728)\end{array}$ & $<20 \mathrm{~mm}$ & $0(0 / 0)$ & $\begin{array}{c}1668 \\
(823 / 845)\end{array}$ \\
\hline $\begin{array}{l}\text { Mori }^{21} \\
\text { (2015) }\end{array}$ & Japan & Polyps & Pre & NA & NA & NA & $\begin{array}{c}148 \\
(73 / 75)\end{array}$ & $<20 \mathrm{~mm}^{*}$ & $0(0 / 0)$ & $42(21 / 21)$ \\
\hline $\begin{array}{l}\text { Osada }^{24} \\
(2016)\end{array}$ & Japan & Patients & NA & $\begin{array}{c}26 \\
(13 / 13)\end{array}$ & $\begin{array}{c}13 \\
(9 / 4)\end{array}$ & $\begin{array}{c}67.5 \\
(68.8 / 66.2)\end{array}$ & $\begin{array}{c}26 \\
(13 / 13)\end{array}$ & $\geq 20 \mathrm{~mm}$ & $\begin{array}{c}26 \\
(13 / 13)\end{array}$ & $\begin{array}{c}18 \\
(8 / 10)\end{array}$ \\
\hline $\begin{array}{l}\text { Pohl }^{26} \\
(2019)\end{array}$ & US & Patients & Pre & $\begin{array}{c}919 \\
(455 / 464)\end{array}$ & $\begin{array}{c}547 \\
(265 / 282)\end{array}$ & $\begin{array}{c}65.1 \\
(65.1 / 65.1)\end{array}$ & $\begin{array}{c}989 \\
(490 / 499)\end{array}$ & $\geq 20 \mathrm{~mm}^{*}$ & $\begin{array}{c}989 \\
(490 / 499)\end{array}$ & $\begin{array}{c}658 \\
(327 / 331)\end{array}$ \\
\hline
\end{tabular}




\begin{tabular}{|c|c|c|c|c|c|c|c|c|c|c|}
\hline $\begin{array}{l}\text { Shioji }{ }^{19} \\
(2003)\end{array}$ & Japan & Polyps & Post & $\begin{array}{c}323 \\
(156 / 167)\end{array}$ & $\begin{array}{c}248 \\
(118 / 130)\end{array}$ & $\begin{array}{c}63.5 \\
(64 / 63)\end{array}$ & $\begin{array}{c}413 \\
(205 / 208)\end{array}$ & $<20 \mathrm{~mm}$ & $\begin{array}{c}0 \\
(0 / 0)\end{array}$ & $\begin{array}{c}187 \\
(97 / 90)\end{array}$ \\
\hline $\begin{array}{l}\text { Zhang }^{22} \\
\text { (2015) }\end{array}$ & China & Patients & NA & $\begin{array}{c}348 \\
(174 / 174)\end{array}$ & $\begin{array}{c}219 \\
(112 / 107)\end{array}$ & $\begin{array}{c}66.05 \\
(67.9 / 64.2)\end{array}$ & $\begin{array}{c}348 \\
(174 / 174)\end{array}$ & $\begin{array}{l}\text { polyps of any } \\
\text { size } \\
(36 \% \geq 20 \mathrm{~mm})\end{array}$ & $\begin{array}{c}130 \\
(63 / 67)\end{array}$ & $\begin{array}{c}101 \\
(50 / 51)\end{array}$ \\
\hline
\end{tabular}


Table 2 Meta-analysis of overall risk of Post-Polypectomy Bleeding (PPB) - Meta-regression results

\begin{tabular}{|c|c|c|c|c|c|c|}
\hline \multirow[b]{2}{*}{ Variable } & \multicolumn{3}{|c|}{$\begin{array}{c}\text { Univariate } \\
\text { Meta-regression analysis }\end{array}$} & \multicolumn{3}{|c|}{$\begin{array}{c}\text { Multivariate } \\
\text { Meta-regression analysis }\end{array}$} \\
\hline & $\mathbf{R R}$ & $95 \% \mathrm{CI}$ & P-value & $\mathbf{R R}$ & $95 \% \mathrm{CI}$ & P-value \\
\hline $\begin{array}{l}\text { No. of participants } \\
\text { (per 100-individual increase) }\end{array}$ & 1.03 & $1.00-1.06$ & 0.051 & 1.01 & $0.98-1.05$ & 0.438 \\
\hline Mean patient age, year & & & & & & \\
\hline$<66$ years & 1 & & & & & \\
\hline$>65$ years & 0.54 & $0.23-1.26$ & 0.155 & & & \\
\hline Country & & & $\nabla$ & & & \\
\hline US/Europe & 1 & & & & & \\
\hline Asia & 0.99 & $0.33-3.00$ & 0.991 & & & \\
\hline Percentage of male participants & 0.99 & $0.40-0.33$ & 0.957 & & & \\
\hline Percentage of large lesions & 0.92 & $0.85-0.98$ & 0.017 & 0.92 & $0.86-0.99$ & 0.042 \\
\hline Percentage of proximal lesions & 0.88 & $0.74-1.05$ & 0.152 & & & \\
\hline Percentage of non-polypoid lesions & 1.27 & $0.21-7.54$ & 0.792 & & & \\
\hline $\begin{array}{l}\text { Percentage of non-pedunculated } \\
\text { lesions }\end{array}$ & 0.14 & $0.01-4.21$ & 0.256 & & & \\
\hline Percentage of adenomatous lesions & 1.10 & $0.78-1.52$ & 0.680 & & & \\
\hline Percentage of serrated lesions & 0.11 & $0.00-5.72$ & 0.276 & & & \\
\hline $\begin{array}{l}\text { Percentage of patients with } \\
\text { antiplatelet therapy }\end{array}$ & 0.02 & $0.00-3.78$ & 0.144 & & & \\
\hline
\end{tabular}




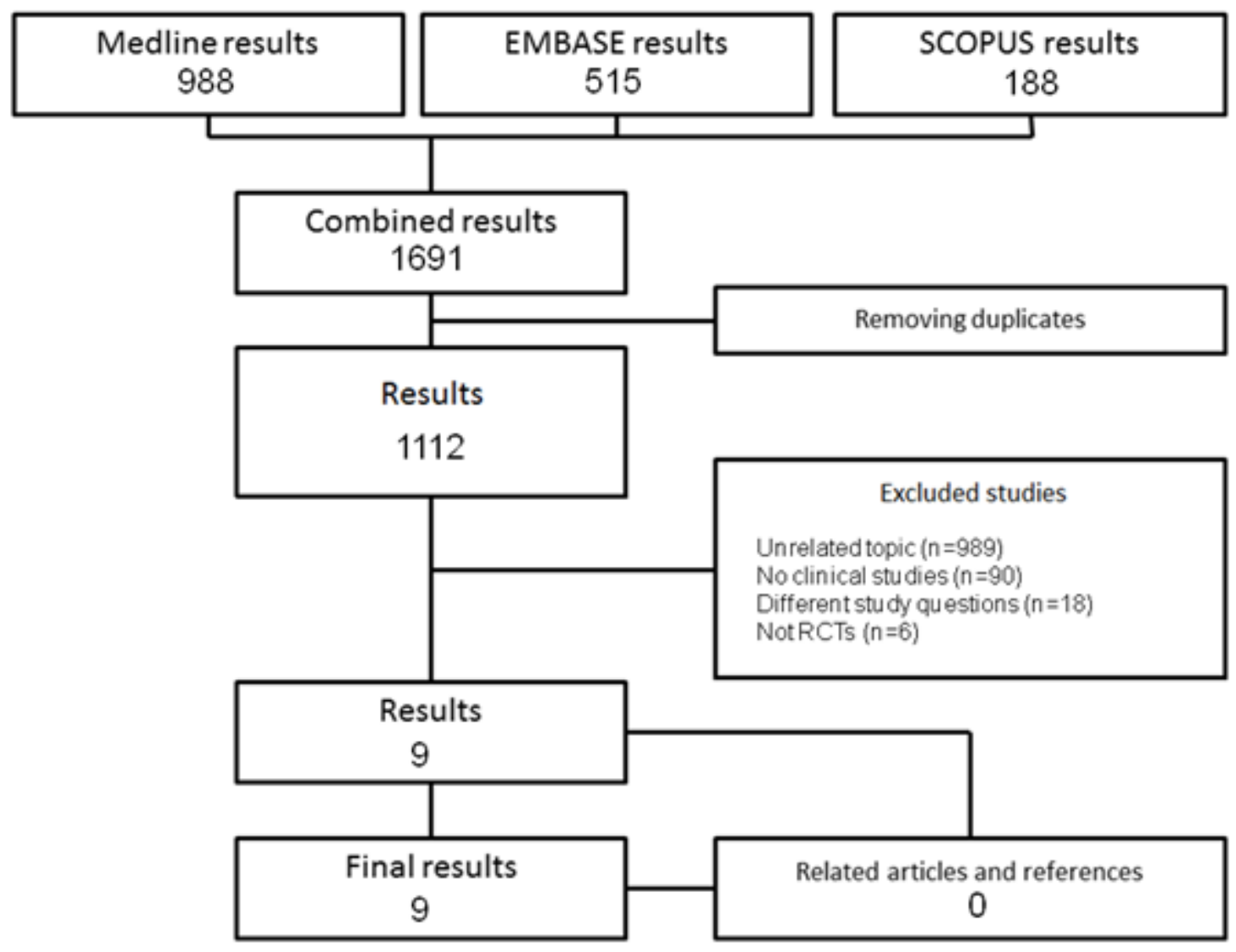




\section{Study}

Studies $w \geq 20 \mathrm{~mm}$

Osada (2016)

Albeniz (2019)

Dokoshi (2015)

Zhang (2015)

Pohl (2019)

Feagins (2019)

Random effects model

Heterogeneity: $\left.\right|^{2}=5 \%, p=0.39$

Studies w/o $\geq 20 \mathrm{~mm}$

Mori (2015)

Shioji (2003)

Matsumoto (2016)

Random effects model

Heterogeneity: $I^{2}=0 \%, p=0.65$

Random effects model

3544

Prediction interval

Heterogeneity: $I^{2}=31 \%, p=0.17$

Residual heterogeneity: $I^{2}=0 \%, p=0.53$

$0 \quad 13$

$\begin{array}{ll}6 & 119\end{array}$

$4 \quad 154$

$2 \quad 174$

16490

12680

1630
Unclipped

Events Total Events Total

$\begin{array}{rrrrr}2 & 73 & & 0 & 75 \\ 2 & 205 & & 2 & 208 \\ 18 & 1636 & & 15 & 1728 \\ & 1914 & & 2011\end{array}$

$\begin{array}{rr}0 & 13 \\ 14 & 116 \\ 3 & 134 \\ 12 & 174 \\ 33 & 499 \\ 15 & 706 \\ & 1642\end{array}$

Risk Ratio

$\mathbf{R R} \quad[95 \% \mathrm{Cl}]$

$1.00 \quad[0.02 ; 46.84]$

$0.42 \quad[0.17 ; 1.05]$

$1.16 \quad[0.26 ; 5.09]$

$0.17 \quad[0.04 ; 0.73]$

$0.49 \quad[0.28 ; 0.89]$

$0.83 \quad[0.39 ; 1.76]$

$0.54 \quad[0.36 ; 0.81]$

$5.14[0.25 ; 105.17]$

$1.01 \quad[0.14 ; 7.13]$

$1.27 \quad[0.64 ; 2.51]$

$1.32 \quad[0.70 ; 2.47]$

$0.69[0.45 ; 1.08]$

$[0.26 ; 1.88]$ $\begin{array}{lllll}0.01 & 0.1 & 1 & 10 & 100\end{array}$

favours clipping favours not clipping 


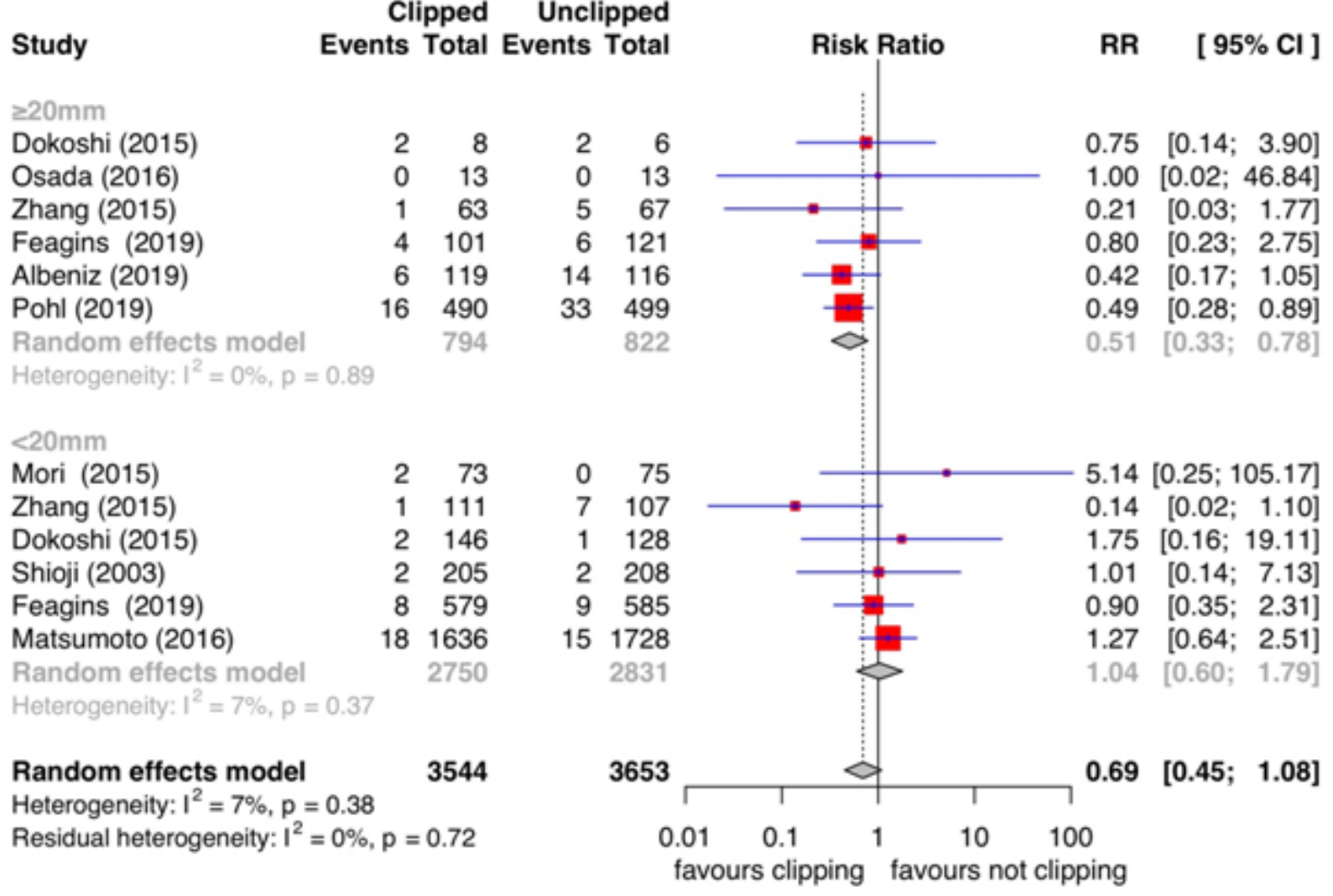




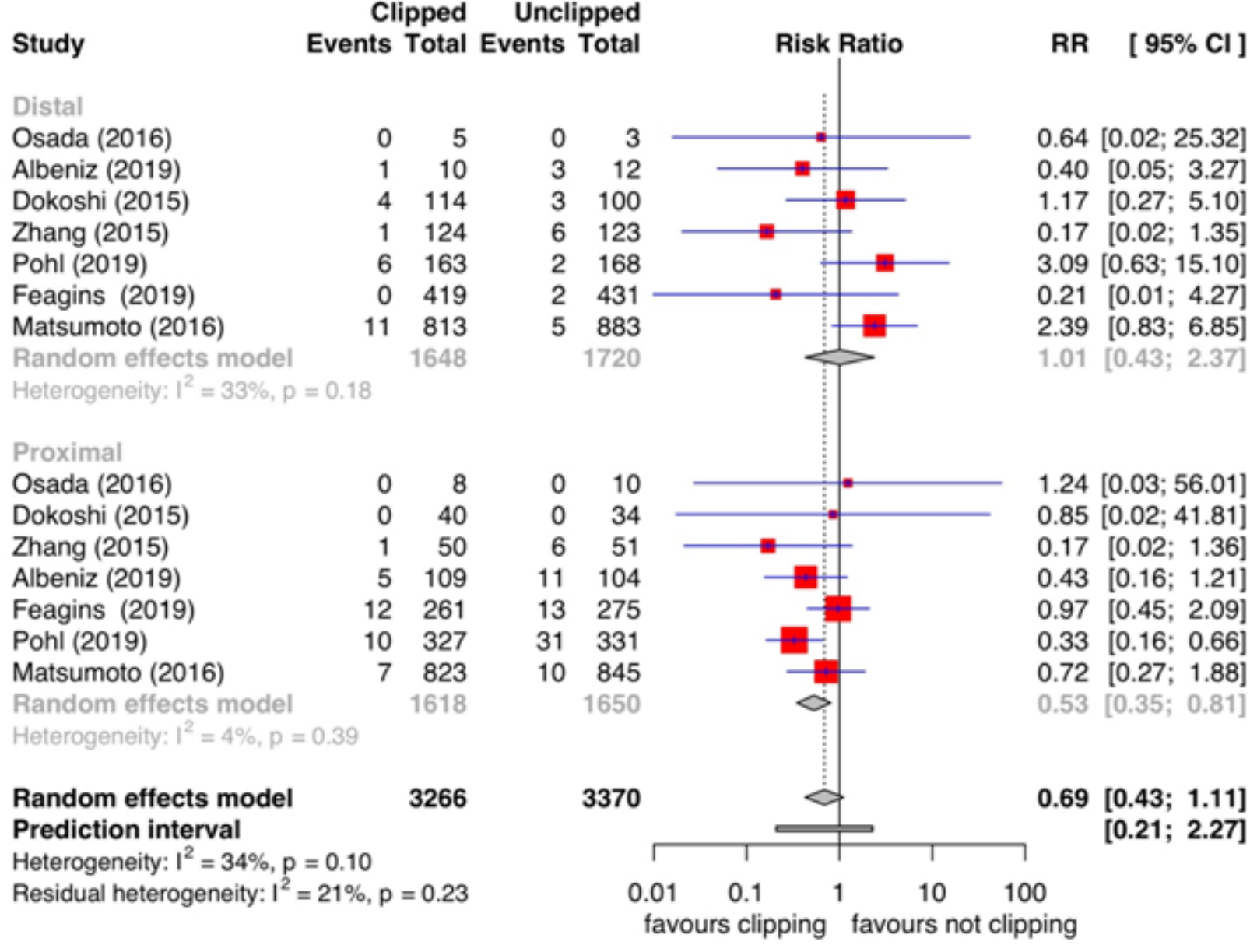




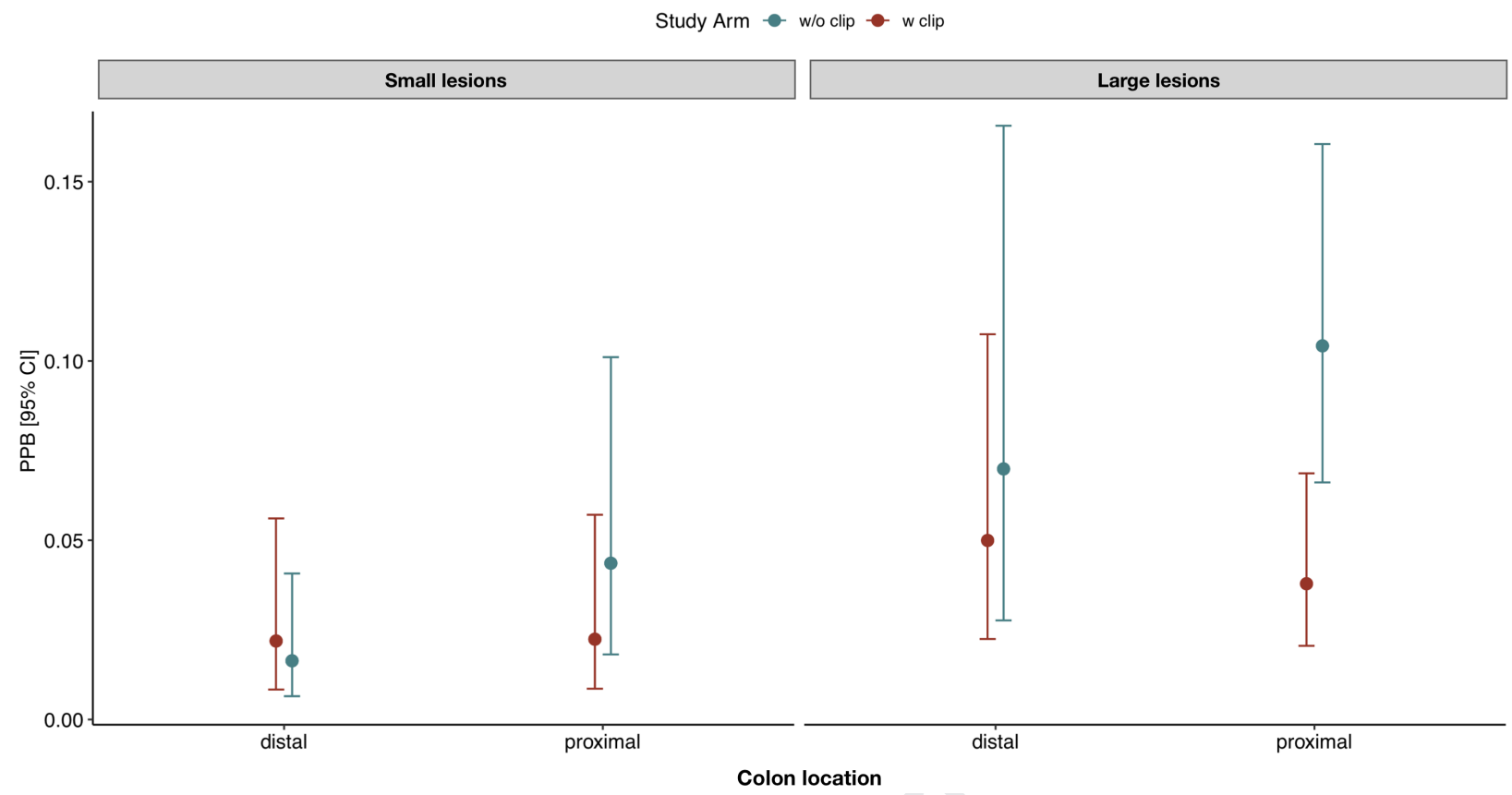




\section{Appendix 1}

\section{Data sources and search strategy}

We performed a comprehensive literature search in PubMed, EMBASE and SCOPUS (up to October $25^{\text {th }}$ 2019) electronic databases to identify studies evaluating the role of prophylactic clipping in preventing postpolypectomy bleeding. PROSPERO was searched for ongoing or recently completed systematic reviews. Electronic searches were supplemented by manual searches of references of included studies and review articles.

We identified studies using the following medical subject headings (MeSH) and the keywords "clip", "clipping", "polypectomy", "bleeding" and "endoscopic resection". The search was restricted to English language.

The Medline search strategy was: "((()(("surgical instruments"[MeSH Terms] OR ("surgical"[All Fields] AND "instruments"[All Fields]) OR "surgical instruments"[All Fields] OR "clip"[All Fields]) AND polypectomy[All Fields]) OR (("surgical instruments"[MeSH Terms] OR ("surgical"[All Fields] AND "instruments"[All Fields]) OR "surgical instruments"[All Fields] OR "clip"[All Fields]) AND endosopic[All Fields] AND resection[All Fields])) OR (("surgical instruments"[MeSH Terms] OR ("surgical"[All Fields] AND "instruments"[All Fields]) OR "surgical instruments"[All Fields] OR "clip"[All Fields]) AND ("hemorrhage"[MeSH Terms] OR "hemorrhage"[All Fields] OR "bleeding"[All Fields]) AND ("prevention and control"[Subheading] OR ("prevention"[All Fields] AND "control"[All Fields]) OR "prevention and control"[All Fields] OR "prophylaxis"[All Fields]))) OR (clipping[All Fields] AND polypectomy[All Fields])) OR (clipping[All Fields] AND endosopic[All Fields] AND resection[All Fields])) OR (clipping[All Fields] AND ("hemorrhage"[MeSH Terms] OR "hemorrhage"[All Fields] OR "bleeding"[All Fields]) AND ("prevention and control"[Subheading] OR ("prevention"[All Fields] AND "control"[All Fields]) OR "prevention and control"[All Fields] OR "prophylaxis"[All Fields]))"

\section{Selection process}

Two review authors (M.S.; R.M.) independently screened the titles and abstracts yielded by the search against the inclusion criteria. Full reports were obtained for all titles that appeared to meet the inclusion criteria or where there was any uncertainty. Review author pairs then screened the full text and abstract reports and decided whether these met the inclusion criteria. Disagreements were resolved through discussion of all the authors. The reasons for excluding trials were recorded. Neither of the review authors was blinded to the journal titles or to the study authors or institutions. When there were multiple articles for a single study, we used the latest publication and supplemented it, if necessary, with data from the more complete version. 


\section{Data extraction}

Using standardized forms, two reviewers (M.S.; R.M.) extracted data independently and in duplicate from each eligible study. Reviewers resolved disagreements by discussion. Unresolved disagreements were resolved by two arbitrators (C.H.; A.R.). The following data were extracted for each study including the publication status, the study design and location, the number of centers involved, the number of patients, patient characteristics (mean/median age, gender, anti-thrombotic therapies), the number of all lesions, the number of procedures, mean/median lesion size, lesion location (proximal, distal), lesion aspect and histology, adverse events (bleedings, perforation surgery), mean/median lesion size. The corresponding authors of the included studies were asked for missing data.

\section{Quality assessment}

Quality was assessed by the Cochrane risk bias tool for randomized studies. Two reviewers (M.S., R.M.) assessed quality measures for included studies and discrepancies were adjudicated by collegial discussion. The overall quality of evidence was appraised by applying GRADE methodology ${ }^{1}$ for the primary outcomes

\section{Multilevel (random-effects) model: meta-analysis of rates of PPB with clipping in comparison to not- clipping.}

The effect size of the meta-analysis was the transformed logit proportion of PPB. The current meta-analysis included studies reporting multiple effect sizes (one for each study arm). Multiple effects sizes within the same study may be correlated, violating the assumption of statistical independence. Thus, a multilevel metaanalytic model was employed, taking into account the potential clustering effects within studies. This approach adds random effects for each effect size within each study to the traditional random-effect model. Therefore, there are two random effects: the first random effect represents the variability between effect sizes assessed in the same study (i.e., between-outcomes or within-study variance), whereas the second random effect represents the variability among the effects observed in different studies (i.e., the between-study variance). For model fitting, we used the rma.mv function in metafor package in $\mathrm{R}_{\text {package }}^{2}$.

The random effects at the level of outcome and study were specified as a list of one-sided formulas in the random argument of the rma.mv function. The REML method was used and It was assumed a compound symmetry structure for the random effects (i.e., the correlation coefficient $\rho$ for the correlation between the different outcomes was constant across studies). The model assumed independent sampling errors of effect size estimates. This is an appropriate assumption because there was no overlap in the patients used to compute outcome data in the two study arms. Subsequently, the multilevel model was extended by including predictor variables of delayed bleeding events (i.e., study arm, prevalence of large lesions and proximal colon location) in an attempt to find variables that moderate the effect. We also considered appropriate interactions between these variables. Data were presented as odds ratios (ORs) and 95\% CIs. 
1. Guyatt G, Oxman AD, Akl EA, Kunz R, Vist G, Brozek J, Norris S, Falck-Ytter Y, Glasziou P, DeBeer H, Jaeschke R, Rind D, Meerpohl J, Dahm P, Schünemann HJ. GRADE guidelines: 1. Introduction-GRADE evidence profiles and summary of findings tables. J Clin Epidemiol 2011; 64: 383-394.

2. Viechtbauer, W. (2010). Conducting meta-analyses in $\mathrm{R}$ with the metafor package. Journal of Statistical Software, 36(3), 1-48. URL: http://www.jstatsoft.org/v36/i03/ 
Appendix 2. Supplemental Table 1: Evaluation of bias of RCTs included in the meta-analysis.

\begin{tabular}{|c|l|l|l|l|l|l|l|}
\hline Study & $\begin{array}{c}\text { Random } \\
\text { sequence } \\
\text { generation }\end{array}$ & $\begin{array}{c}\text { Allocation } \\
\text { Concealmen } \\
\mathbf{t}\end{array}$ & $\begin{array}{c}\text { Blinding of } \\
\text { participants } \\
\text { and } \\
\text { personnel }\end{array}$ & $\begin{array}{c}\text { Blinding of } \\
\text { outcome } \\
\text { assessment }\end{array}$ & $\begin{array}{c}\text { Adequate } \\
\text { assessment } \\
\text { of } \\
\text { incomplete } \\
\text { outcome }\end{array}$ & $\begin{array}{c}\text { Selective } \\
\text { reporting } \\
\text { avoided }\end{array}$ & $\begin{array}{c}\text { No other } \\
\text { bias }\end{array}$ \\
\hline Albeniz (2019) & Low Risk & Low Risk & High risk & High risk & Low Risk & Low Risk & Low Risk \\
\hline Dokoshi (2015) & Unclear risk & Low Risk & High risk & High risk & Low Risk & Low Risk & Low Risk \\
\hline Feagins (2019) & Low Risk & Low Risk & High risk & High risk & Low Risk & Low Risk & Low Risk \\
\hline $\begin{array}{c}\text { Matsumoto } \\
(2016)\end{array}$ & Low Risk & Unclear risk & High risk & High risk & Low Risk & Low Risk & Low Risk \\
\hline Mori (2015) & Low Risk & Low Risk & High risk & High risk & Low Risk & Low Risk & Low Risk \\
\hline Osada (2016) & Unclear risk & Low Risk & High risk & High risk & Low Risk & Low Risk & Low Risk \\
\hline Pohl (2019) & Low Risk & Low Risk & High risk & High risk & Low Risk & Low Risk & Low Risk \\
\hline Shioji (2003) & Unclear risk & Low Risk & High risk & High risk & Low Risk & Low Risk & Low Risk \\
\hline Zhang (2015) & Unclear risk & Low Risk & High risk & High risk & Low Risk & Low Risk & Low Risk \\
\hline
\end{tabular}


Appendix 2, Supplemental Table 2 Meta-Analysis of by-polyp delayed post-polypectomy bleeding events and clips use: "Leave-One-Out" Sensitivity.

\begin{tabular}{|c|c|c|c|c|c|c|c|c|}
\hline & \multicolumn{4}{|c|}{ Influential analysis (Fixed effects model) } & \multicolumn{4}{|c|}{ Influential analysis Random effects model) } \\
\hline & $\begin{array}{c}\text { RR } \\
{[95 \%-C I]}\end{array}$ & p-value & tau2 & $\mathbf{I} 2$ & $\begin{array}{c}\text { RR } \\
{[95 \%-C I]}\end{array}$ & p-value & tau2 & $\mathbf{I} 2$ \\
\hline $\begin{array}{c}\text { Omitting } \\
\text { Albeniz (2019) }\end{array}$ & $\begin{array}{c}0.72 \\
{[0.51 ; 1.00]}\end{array}$ & 0.051 & 0.140 & $32.10 \%$ & $\begin{array}{c}0.76 \\
{[0.46 ; 1.23]}\end{array}$ & 0.265 & 0.140 & $32.09 \%$ \\
\hline $\begin{array}{c}\text { Omitting } \\
\text { Dokoshi }(2015)\end{array}$ & $\begin{array}{c}0.65 \\
{[0.47 ; 0.90]}\end{array}$ & 0.010 & 0.155 & $37.00 \%$ & $\begin{array}{c}0.66 \\
{[0.41 ; 1.08]}\end{array}$ & 0.096 & 0.155 & $36.94 \%$ \\
\hline $\begin{array}{c}\text { Omitting } \\
\text { Feagins (2019) }\end{array}$ & $\begin{array}{c}0.64 \\
{[0.45 ; 0.91]}\end{array}$ & 0.012 & 0.200 & $38.20 \%$ & $\begin{array}{c}0.67 \\
{[0.39 ; 1.14]}\end{array}$ & 0.145 & 0.199 & $38.12 \%$ \\
\hline $\begin{array}{l}\text { Omitting } \\
\text { Matsumoto } \\
(2016)\end{array}$ & $\begin{array}{c}0.56 \\
{[0.39 ; 0.803]}\end{array}$ & 0.002 & 0.031 & $8.40 \%$ & $\begin{array}{c}0.58 \\
{[0.39 ; 0.88]}\end{array}$ & 0.009 & 0.031 & $8.28 \%$ \\
\hline $\begin{array}{l}\text { Omitting Mori } \\
\text { (2015) }\end{array}$ & $\begin{array}{c}0.65 \\
{[0.47 ; 0.89]}\end{array}$ & 0.008 & 0.104 & $29.40 \%$ & $\begin{array}{c}0.67 \\
{[0.43 ; 1.02]}\end{array}$ & 0.064 & 0.104 & $29.39 \%$ \\
\hline $\begin{array}{l}\text { Omitting Osada } \\
\text { (2016) }\end{array}$ & $\begin{array}{c}0.67 \\
{[0.49 ; 0.92]}\end{array}$ & 0.013 & 0.162 & $39.50 \%$ & $\begin{array}{c}0.69 \\
{[0.43 ; 1.10]}\end{array}$ & 0.122 & 0.161 & $39.44 \%$ \\
\hline $\begin{array}{l}\text { Omitting Pohl } \\
\text { (2019) }\end{array}$ & $\begin{array}{c}0.77 \\
{[0.52 ; 1.11]}\end{array}$ & 0.163 & 0.147 & $28.60 \%$ & $\begin{array}{c}0.77 \\
{[0.46 ; 1.29]}\end{array}$ & 0.320 & 0.147 & $28.51 \%$ \\
\hline $\begin{array}{c}\text { Omitting Shioji } \\
\text { (2003) }\end{array}$ & $\begin{array}{c}0.66 \\
{[0.48 ; 0.91]}\end{array}$ & 0.012 & 0.163 & $38.90 \%$ & $\begin{array}{c}0.68 \\
{[0.42 ; 1.10]}\end{array}$ & 0.115 & 0.162 & $38.84 \%$ \\
\hline $\begin{array}{c}\text { Omitting Zhang } \\
\text { (2015) }\end{array}$ & $\begin{array}{c}0.74 \\
{[0.536 ; 1.03]}\end{array}$ & 0.077 & 0.033 & $11.00 \%$ & $\begin{array}{c}0.75 \\
{[0.52 ; 1.09]}\end{array}$ & 0.137 & 0.032 & $10.92 \%$ \\
\hline Pooled estimate & $\begin{array}{c}0.67 \\
{[0.49 ; 0.92]}\end{array}$ & 0.013 & 0.126 & $31.10 \%$ & $\begin{array}{c}0.69 \\
{[0.45 ; 1.08]}\end{array}$ & 0.072 & 0.126 & $27.54 \%$ \\
\hline
\end{tabular}




\section{Journal Pre-proof}

Appendix 2, Supplemental Table 3 Multilevel meta-regression analysis of PPB events.

\begin{tabular}{|c|c|c|c|}
\hline & Ors & 95\% CI & P-value \\
\hline Unclipped polyps (reference level) & 1 & & \\
\hline Clipped polyps & 1.06 & $(0.66-1.75)$ & 0.804 \\
\hline $\begin{array}{c}\text { Percentage of large lesions } \\
\text { (as a continuous variable) }\end{array}$ & 1.28 & $(1.16-1.42)$ & $<0.001$ \\
\hline Use of Clip x Percentage of large lesions & 0.92 & $0.85-0.98$ & 0.016 \\
\hline $\begin{array}{c}\text { Percentage of proximal lesions } \\
\text { (as a continuous variable) }\end{array}$ & 0.86 & $(0.67-1.10)$ & 0.223 \\
\hline
\end{tabular}


Appendix 2, Supplemental Table 4 - A multilevel random effect model with study arm, polyp lesion (large vs. small polyps), and their interaction term was fitted to the data. The two-way interaction term between polyp size and study arm was statistically significant. Results from the model shows a protective effect of clipping for large polyps (clipped large vs. unclipped large, OR, 0.54; 95\% CI:0.30-0.97), while no protective effect of clipping was seen among small polyps (clipped small vs. unclipped small, OR:0.79; 95\% CI:0.43-1.44; $\mathrm{p}=0.435$ ).

\begin{tabular}{|c|c|c|c|}
\hline & \multicolumn{2}{|c|}{ Multilevel Meta-regression analysis } \\
\hline $\begin{array}{c}\text { Clipped large vs. Unclipped large } \\
\text { polyps }\end{array}$ & 0.54 & $(0.30-0.97)$ & 0.041 \\
\hline $\begin{array}{c}\text { Ons } \\
\text { Unclipped small polyps vs. }\end{array}$ & 0.22 & $(0.12-0.40)$ & $<0.001$ \\
\hline $\begin{array}{c}\text { Clipped large polyps } \\
\text { polyps }\end{array}$ & 0.79 & $0.43-1.44$ & 0.435 \\
\hline $\begin{array}{c}\text { Clipped small vs. Clipped large } \\
\text { polyps }\end{array}$ & 0.36 & $(0.19-0.66)$ & $<0.001$ \\
\hline
\end{tabular}


Appendix 2, Supplemental Table 5 - A multilevel random effect model with study arm, proximal colon location and their interaction term was fitted to the data. The two-way interaction term between colon location and study arm was statistically significant $(\mathrm{p}=0.017)$. Results from the model shows a protective effect of clipping for proximal polyps (clipped proximal vs. unclipped proximal polyps, OR, 0.46; $95 \%$ CI:0.24-0.88), while no protective effect of clipping was seen among distal polyps (clipped distal vs. unclipped distal polyps, OR:1.21; 95\% CI:0.56-2.62; $\mathrm{p}=0.631$ ). After adjusting for the prevalence of large lesions in the multilevel model, the benefit of clipping in reducing PPB was significant only for large proximal lesions (clipped versus unclipped polyps, OR, 0.34; 95\% CI:0.19-0.65; $\mathrm{p}=0.021$ ), but not for small proximal lesions (clipped versus unclipped polyps, OR, 0.88; 95\% CI:0.48-1.62; $\mathrm{p}=0.581$ ).

\begin{tabular}{|c|c|c|c|}
\hline & \multicolumn{3}{|c|}{ Multilevel Meta-regression analysis } \\
\hline & ORs & $\mathbf{9 5 \%}$ CI & P-value \\
\hline $\begin{array}{c}\text { clipped proximal vs. unclipped } \\
\text { proximal polyps }\end{array}$ & 0.46 & $(0.24-0.88)$ & .0018 \\
\hline $\begin{array}{c}\text { unclipped distal vs. unclipped } \\
\text { proximal polyps }\end{array}$ & 0.42 & $(0.24-0.73)$ & $<0.001$ \\
\hline $\begin{array}{c}\text { clipped distal vs clipped proximal } \\
\text { polyps }\end{array}$ & 1.09 & $(0.61-1.95)$ & 0.764 \\
\hline $\begin{array}{c}\text { clipped distal vs. unclipped distal } \\
\text { polyps }\end{array}$ & 1.21 & $0.56-1.38$ & 0.631 \\
\hline
\end{tabular}


Appendix 2, Supplemental Table 6. GRADE evidence profile for efficacy of clipping vs. no clipping strategy in reducing post procedural bleeding.

* Risk of bias was judged as serious due to the low-moderate quality of the included randomized controlled trials.

** Inconsistency risk was judged as serious due to heterogeneity among patients (i.e. different indications to resection in term of lesion size or location).

\begin{tabular}{|c|c|c|c|c|c|c|c|c|c|}
\hline & \multicolumn{5}{|c|}{ Quality assessment } & \multicolumn{3}{|c|}{ Summary of findings } & Quality \\
\hline $\begin{array}{c}\text { Outcome, } \\
\text { No. of } \\
\text { studies, } \\
\text { design } \\
\text { (no. of } \\
\text { patients) }\end{array}$ & $\begin{array}{l}\text { Risk of } \\
\text { bias }\end{array}$ & $\begin{array}{c}\text { Inconsis } \\
\text { tency }\end{array}$ & $\begin{array}{c}\text { Indirec } \\
\text { tness }\end{array}$ & $\begin{array}{c}\text { Impreci } \\
\text { sion }\end{array}$ & $\begin{array}{c}\text { Publicati } \\
\text { on bias }\end{array}$ & $\begin{array}{l}\text { PPB in } \\
\text { Clipping }\end{array}$ & $\begin{array}{l}\text { PPB in } \\
\text { No } \\
\text { Clipping }\end{array}$ & $\begin{array}{c}\text { Relativ } \\
\text { e Risk } \\
(95 \% \mathrm{C} \\
\text { I) }\end{array}$ & \\
\hline $\begin{array}{c}\text { All } \\
\text { lesions, } \\
\text { 9 RCTs }\end{array}$ & Serious* & $\begin{array}{c}\text { Serious* } \\
*\end{array}$ & $\begin{array}{c}\text { Not } \\
\text { serious }\end{array}$ & $\begin{array}{c}\text { Not } \\
\text { serious }\end{array}$ & $\begin{array}{c}\text { Not } \\
\text { serious }\end{array}$ & $62 / 3,544$ & $94 / 3653$ & $\begin{array}{c}0.69 \\
\\
(0.45- \\
1.08)\end{array}$ & $\begin{array}{c}\oplus \oplus \mathrm{OO} \\
\text { Low }\end{array}$ \\
\hline $\begin{array}{c}\text { Large } \\
(>20 \mathrm{~mm}) \\
\text { lesions, } \\
\text { 6 RCTs }\end{array}$ & Serious* & $\begin{array}{c}\text { Not } \\
\text { serious }\end{array}$ & $\begin{array}{c}\text { Not } \\
\text { serious }\end{array}$ & $\begin{array}{c}\text { Not } \\
\text { serious }\end{array}$ & $\begin{array}{c}\text { Not } \\
\text { serious }\end{array}$ & $29 / 794$ & $60 / 822$ & $\begin{array}{c}0.51 \\
(0.33- \\
0.78)\end{array}$ & $\begin{array}{c}\oplus \oplus \oplus \mathrm{O} \\
\text { Moderat } \\
\mathrm{e}\end{array}$ \\
\hline $\begin{array}{c}\text { Proximal } \\
\text { lesions, } \\
7 \text { RCTs }\end{array}$ & Serious* & $\begin{array}{c}\text { Not } \\
\text { serious }\end{array}$ & $\begin{array}{c}\text { Not } \\
\text { serious }\end{array}$ & $\begin{array}{c}\text { Not } \\
\text { serious }\end{array}$ & $\begin{array}{c}\text { Not } \\
\text { serious }\end{array}$ & $35 / 1618$ & $71 / 1650$ & $\begin{array}{c}0.53 \\
\\
(0.35- \\
0.81)\end{array}$ & $\begin{array}{c}\oplus \oplus \oplus \mathrm{O} \\
\text { Moderat } \\
\mathrm{e}\end{array}$ \\
\hline
\end{tabular}


Appendix 2, Supplemental Table 7. Technical features. NA: Not available.

\begin{tabular}{|c|l|l|}
\hline \multicolumn{1}{|c|}{ Study } & \multicolumn{1}{|c|}{ Electrosurgical generators } & \multicolumn{1}{|c|}{ Clips } \\
\hline Albeniz (2019) & $\begin{array}{l}\text { ERBE (ICC200, VIO 200 or } \\
\text { VIO300); Endocut mode }\end{array}$ & Micro-Tech, Nanjing, China \\
\hline Dokoshi (2015) & $\begin{array}{l}\text { ERBE (ICC200 or VIO300); } \\
\text { Endocut mode }\end{array}$ & $\begin{array}{l}\text { HX-610-135, Olympus, Tokio, } \\
\text { Japan }\end{array}$ \\
\hline Feagins (2019) & NA & NA \\
\hline Matsumoto (2016) & $\begin{array}{l}\text { ERBE (ICC200 or VIO200); } \\
\text { Olympus (ESG-100, PSD.60) }\end{array}$ & NA \\
\hline Mori (2015) & ERBE (VIO300); Swift mode & $\begin{array}{l}\text { HX-610-135, Olympus, Tokio, } \\
\text { Japan }\end{array}$ \\
\hline Osada (2016) & ERBE (VIO300); Endocut mode & $\begin{array}{l}\text { ZEOCLIP ZP-CH ZeonMedical, } \\
\text { Tokio, Japan }\end{array}$ \\
\hline Pohl (2019) & $\begin{array}{l}\text { ERBE generators; Endocut or } \\
\text { forced coagulation modes }\end{array}$ & $\begin{array}{l}\text { Resolution clip, Boston Scientific, } \\
\text { Marlborough, US } \\
\text { Resolution 360 clip, Boston } \\
\text { Scientific, Marlborough, US }\end{array}$ \\
\hline Shioji (2003) & $\begin{array}{l}\text { Olympus (UES-10); blended } \\
\text { current. }\end{array}$ & $\begin{array}{l}\text { HX-5QR-1, Olympus, Tokio, Japan } \\
\text { ERBE (ICC200 or VIO300); } \\
\text { Endocut mode }\end{array}$ \\
\hline Zhang (2015) & $\begin{array}{l}\text { HX-610-135, Olympus, Tokio, } \\
\text { Japan } \\
\text { Resolution clip, Boston Scientific, } \\
\text { Natic, US }\end{array}$ \\
\hline
\end{tabular}


Appendix 3, Supplemental Figure 1: Meta-Analysis of PPB rates of delayed bleeding - a multilevel random effects model accounting for the underlying heterogeneity between and within trials was used to estimate the pooled rates of PPB.

\begin{tabular}{|c|c|c|c|c|}
\hline Author(s) and Year & $P P B$ & $N$ & & PPB Rate $[95 \% \mathrm{CI}]$ \\
\hline Albeniz (2019) w clip & 6 & 119 & $=-1$ & $0.050[0.023,0.108]$ \\
\hline Albeniz (2019) w/o clip & 14 & 116 & $\mapsto-1$ & $0.121[0.073,0.194]$ \\
\hline Dokoshi (2015) w clip & 4 & 154 & $\infty$ & $0.026[0.010,0.067]$ \\
\hline Dokoshi (2015) w/o clip & 3 & 134 & $\infty$ & $0.022[0.007,0.067]$ \\
\hline Feagins (2019) w clip & 12 & 680 & $=$ & $0.018[0.010,0.031]$ \\
\hline Feagins (2019) w/o clip & 15 & 706 & $\because$ & $0.021[0.013,0.035]$ \\
\hline Matsumoto (2016) w clip & 18 & 1636 & $\vdots$ & $0.011[0.007,0.017]$ \\
\hline Matsumoto (2016) w/o clip & 15 & 1728 & 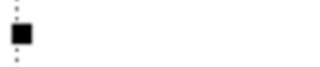 & $0.009[0.005,0.014]$ \\
\hline Mori (2015) w clip & 2 & 73 & 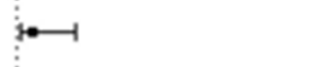 & $0.027[0.007,0.103]$ \\
\hline Mori (2015) w/o clip & 0 & 75 & $\longmapsto$ & $0.007[0.000,0.097]$ \\
\hline Osada (2016) w clip & 0 & 13 & & $0.036[0.002,0.384]$ \\
\hline Osada (2016) w/o clip & 0 & 13 & - & $0.036[0.002,0.384]$ \\
\hline Pohl (2019) w clip & 16 & 490 & - & $0.033[0.020,0.053]$ \\
\hline Pohl (2019) w/o clip & 33 & 499 & $\mathbf{\theta}$ & $0.066[0.047,0.092]$ \\
\hline Shioji (2003) w clip & 2 & 205 & $y$ & $0.010[0.002,0.038]$ \\
\hline Shioji (2003) w/o clip & 2 & 208 & $y-1$ & $0.010[0.002,0.038]$ \\
\hline Zhang (2015) w clip & 2 & 174 & $x$ & $0.011[0.003,0.045]$ \\
\hline Zhang (2015) w/o clip & 12 & 174 & $\uplus-1$ & $0.069[0.040,0.118]$ \\
\hline without Clip & 94 & 3653 & $\triangleright$ & $0.033[0.019,0.057]$ \\
\hline \multirow[t]{3}{*}{ with Clip } & 62 & 3544 & 0 & $0.022[0.012,0.039]$ \\
\hline & & & 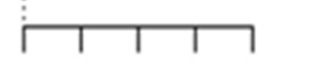 & \\
\hline & & & $.000 \quad 0.200 \quad 0.400$ & \\
\hline
\end{tabular}




\section{Journal Pre-proof}

Appendix 3, Supplemental Figure 2: Funnel plot of publication bias - Ratio Risk of PPB (i.e., postpolypectomy bleeding).

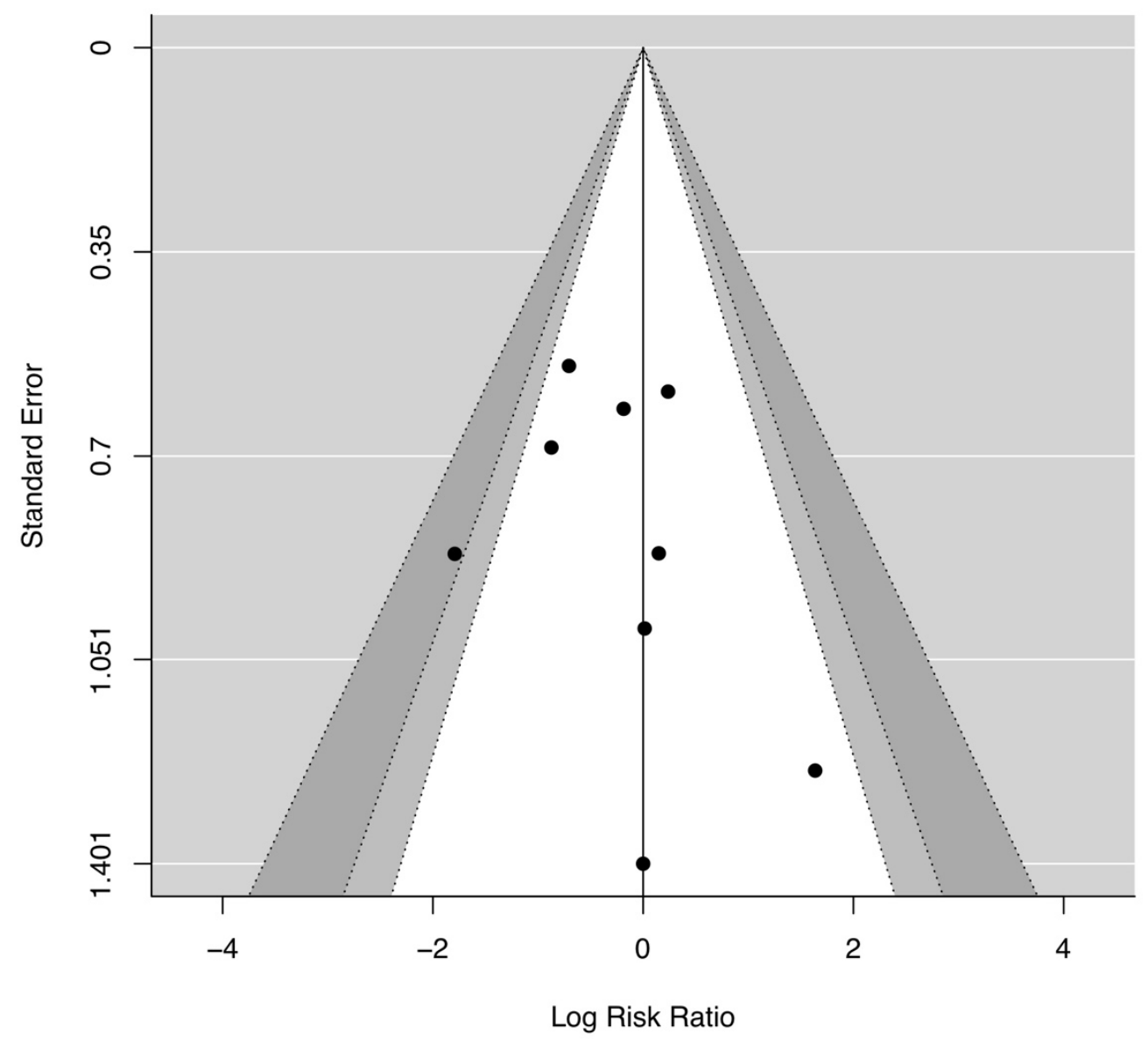


Appendix 3, Supplemental Figure 3: Meta-Analysis of relative risk of post-polypectomy bleeding (PPB) results from per-protocol analysis (i.e., PPB after completion of clipping). The study by Matsumoto had substantial influence on the pooled effect size estimate.

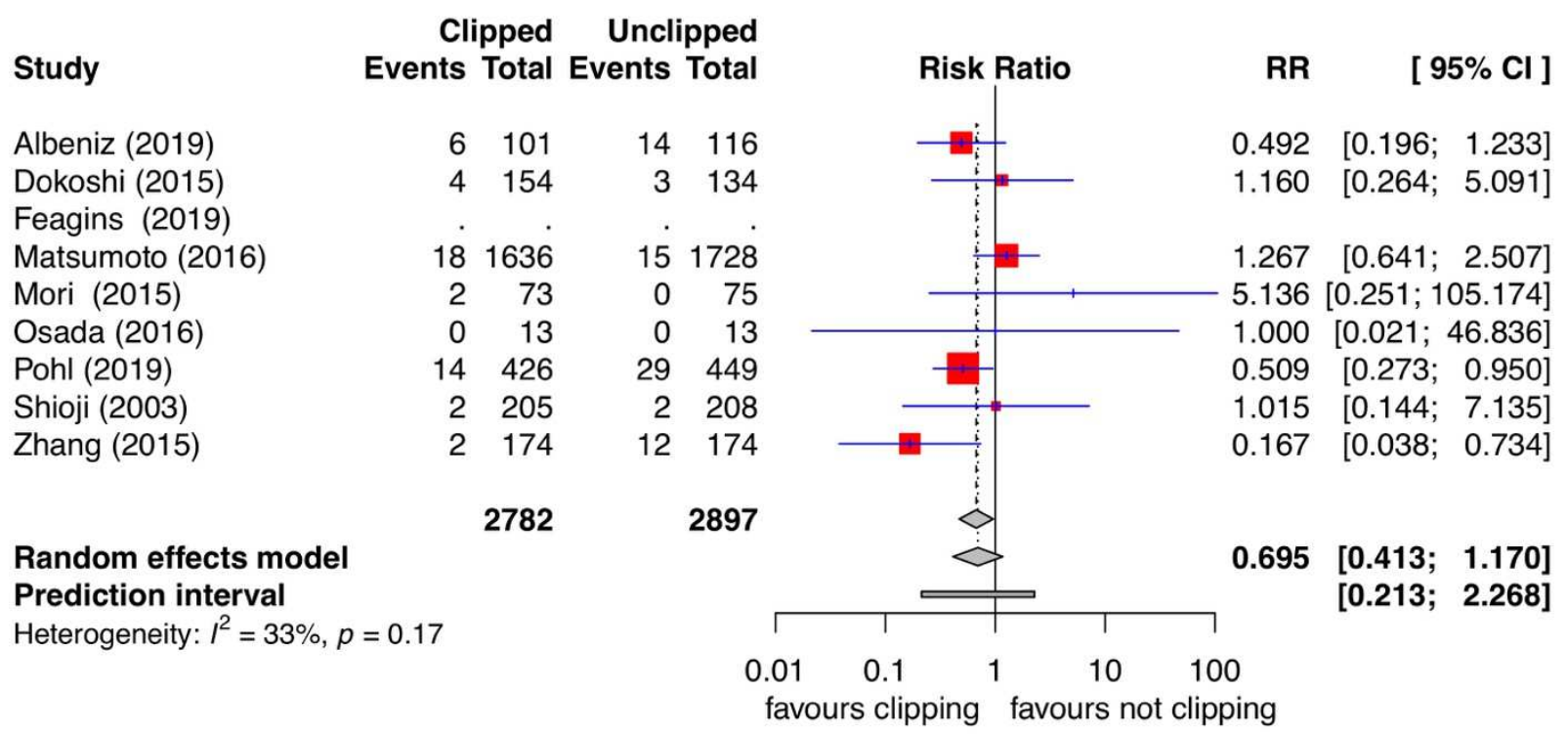


Appendix 3. Supplemental Figure 4 - The Figure shows a plot of the risk ratio estimate (derived from the meta-regression model) as a function of the percentage (decimal number) of large lesions. The estimated risk ratio of PPB associated with clip use was not significantly different from 1 for a prevalence of large lesions of $0 \%$ (only small lesions included, $\mathrm{RR}=1.06$; 95\% CI: 0.66-1.72), indicating an equal PPB risk on average for small clipped and unclipped polyps. However, we found increasingly large effects as the prevalence of large lesions increases. The estimated risk ratios of PPB for clipped (versus unclipped) polyps were 0.69 (95\% CI:0.50-0.95) and 0.44 (95\% CI:0.27-0.72) for percentages of large lesions of 0.50 and 1.00, respectively.

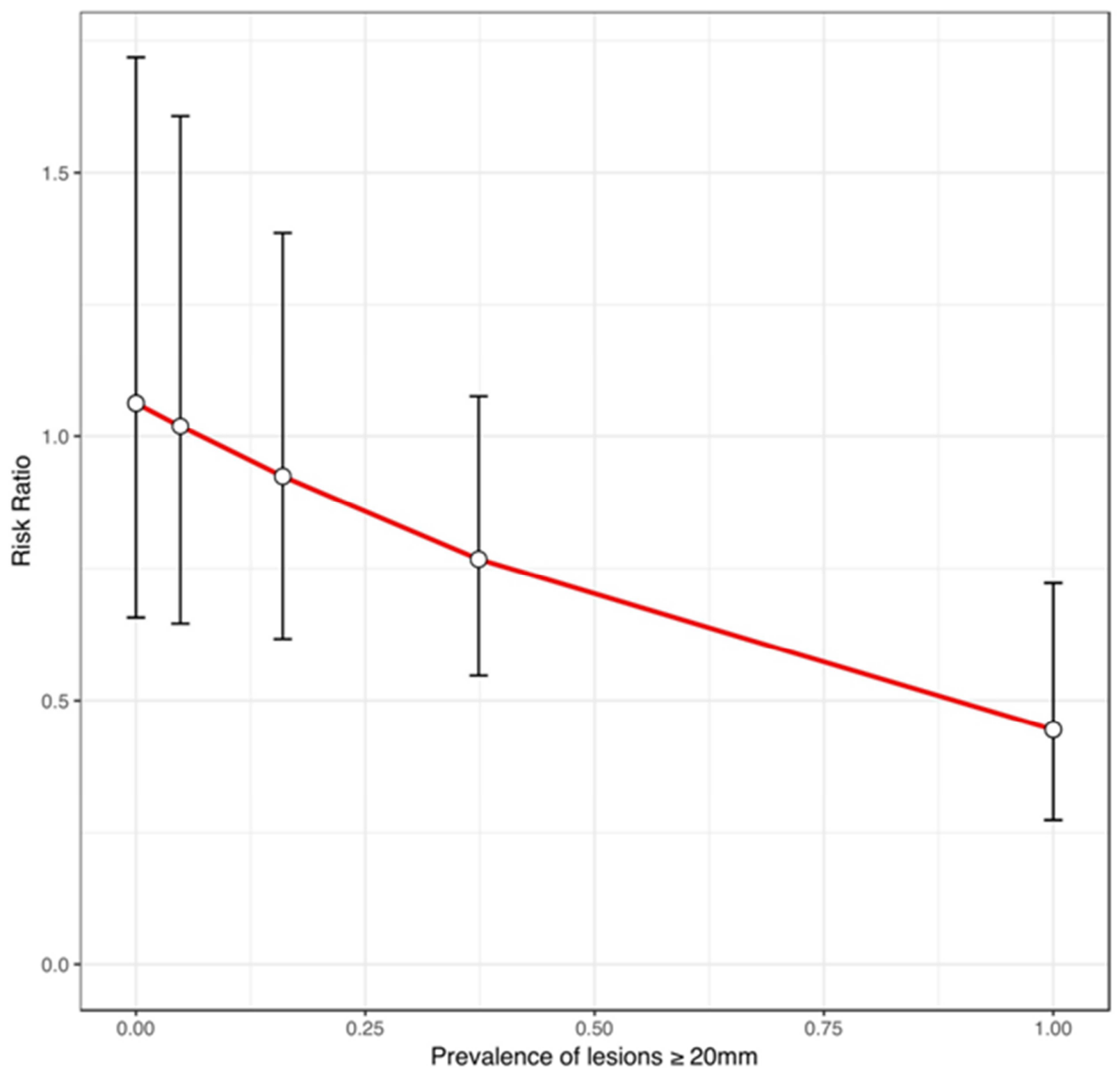


Appendix 3, Supplemental Figure 5: Meta-Analysis of PPB rates for large and small polyps -a multilevel random effects model accounting for the underlying heterogeneity between and within trials was used to estimate the rates of PPB for large and small lesions with and without clips. In our dataset, 3 studies reported data on both large and small lesions, 3 studies only on large lesions and the remaining 3 studies only on small lesions. Therefore, this analysis included 12 effect size estimates ( 6 for each study arm) of PPB among large polyps ( $\mathrm{n}=1616$ polyps) and 12 effect size estimates ( 6 for each study arm) of PPB among small polyps $(\mathrm{n}=5581$ polyps $)$.

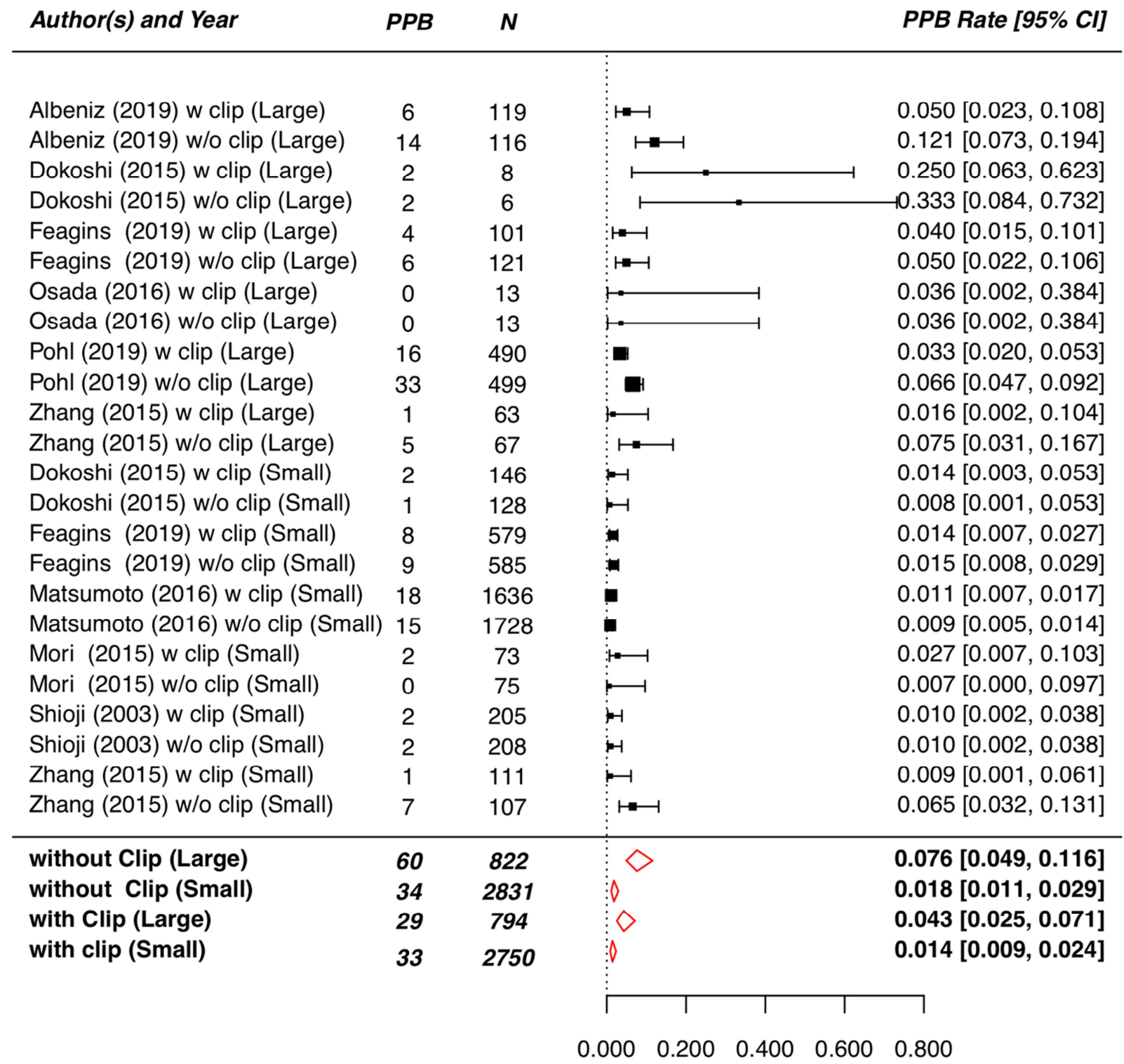

Proportion 
Appendix 3, Supplemental Figure 6: Meta-Analysis of relative risk of delayed bleeding - results from a sensitivity analysis among studies defining proximal lesions as sited proximally to the splenic flexure (including transverse colon).

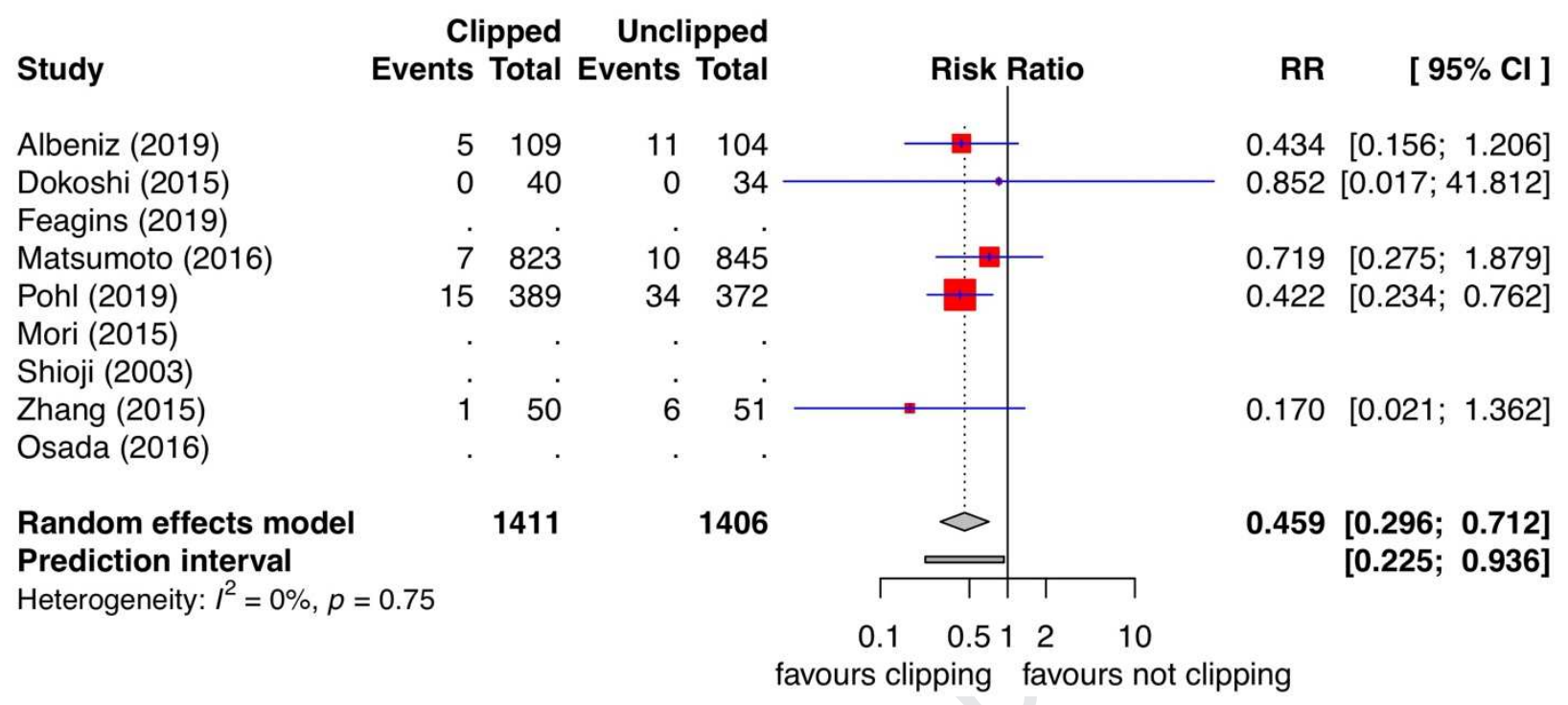


Appendix 3, Supplemental Figure 7: Meta-Analysis of relative risk of delayed bleeding - results from a sensitivity analysis among studies defining proximal lesions as lesions sited in cecum, ascending colon and hepatic flexure.

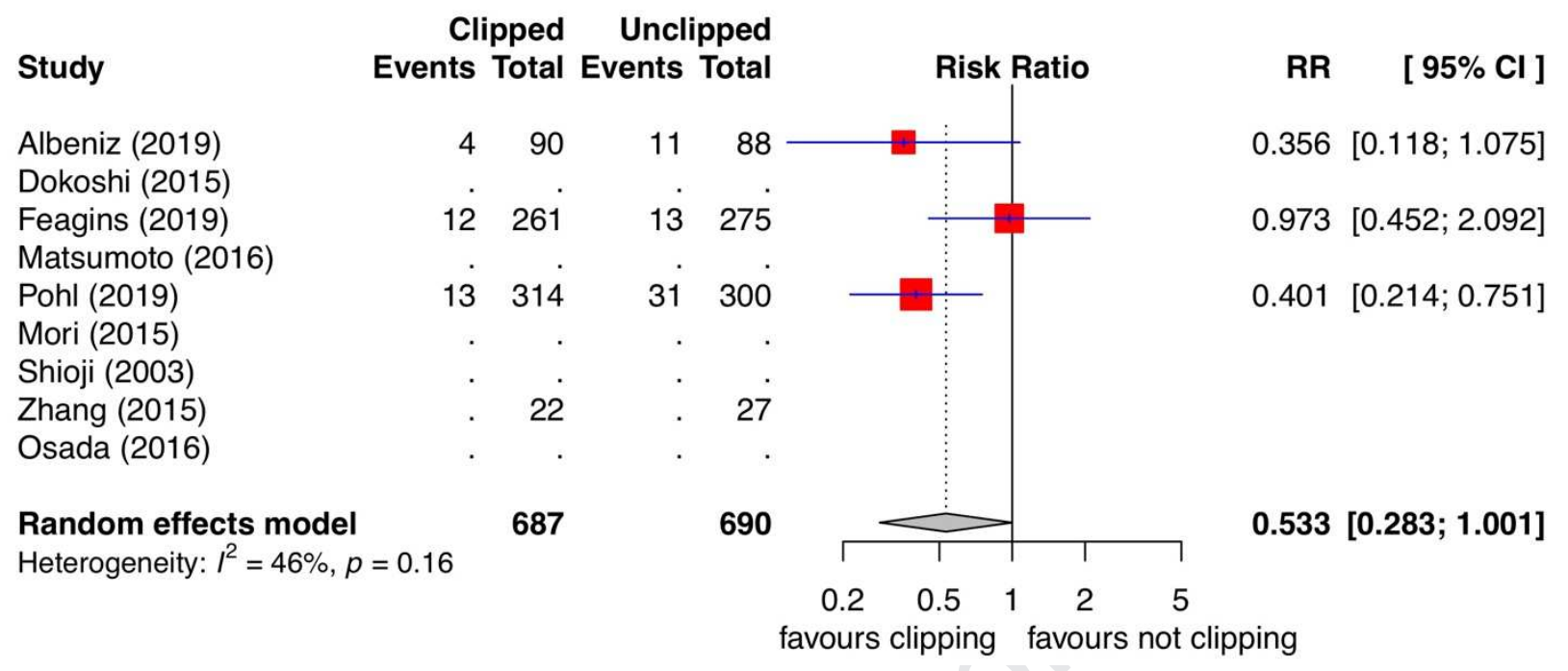


Appendix 3, Supplemental Figure 8: Meta-Analysis of PPB rates of delayed bleeding in the proximal colon location - a multilevel random effects model accounting for the underlying heterogeneity between and within trials was used to estimate the rates of PPB for proximally and distally located lesions with and without clips. The analysis included 7 studies ( $n=6,636$ polyps) with available count data for proximal $(n=3268)$ and distal lesions $(n=3368)$. Therefore, 14 effect size estimates ( 7 for each study arm) of PPB among distal and 14 effect size estimates (7 for each study arm) of PPB among proximal polyps were combined.

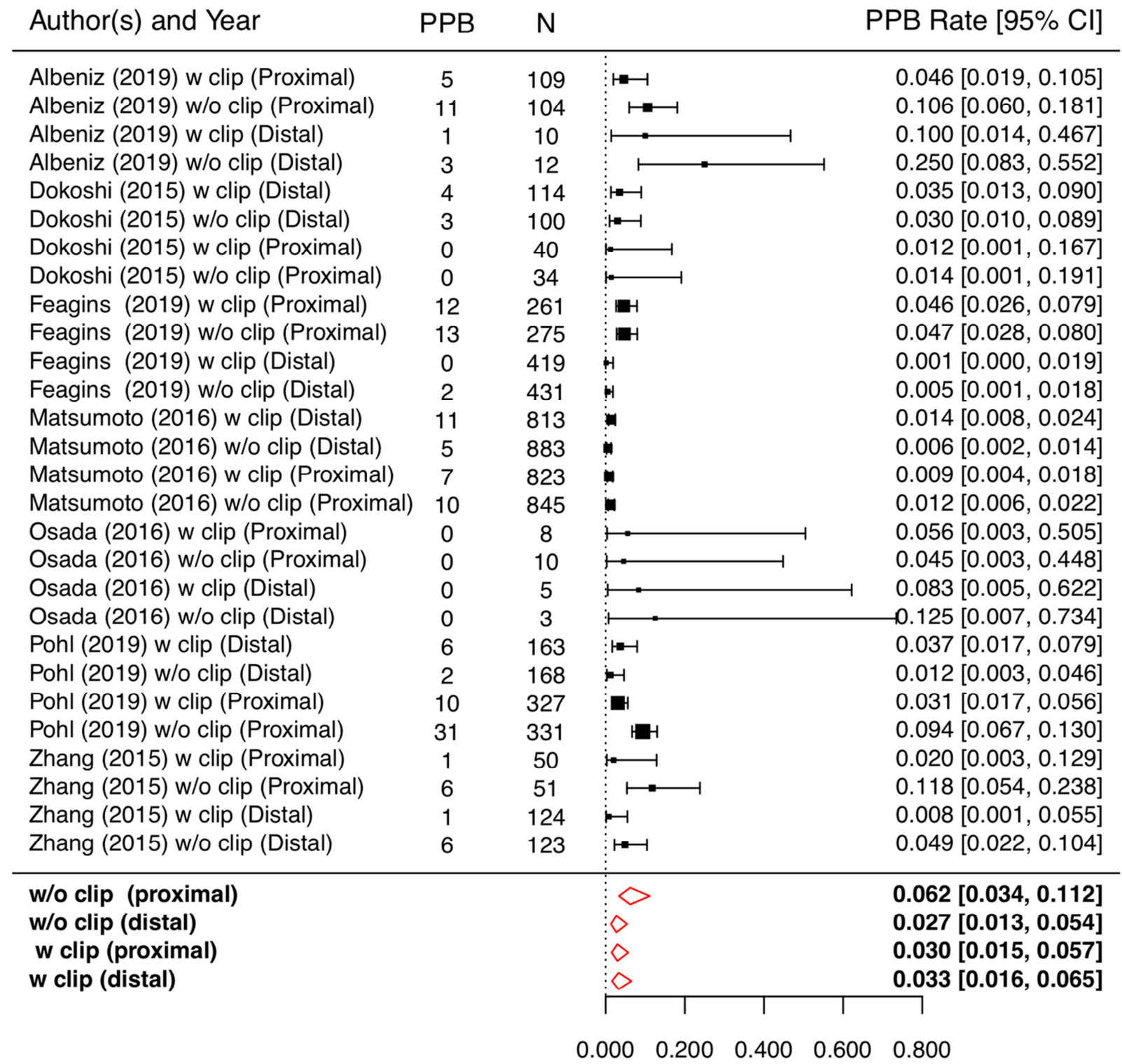

Proportion 
Appendix 3, Supplemental Figure 9: Forest plot, showing the results from a cumulative meta-analysis of the relative risk of PPB for clipped and unclipped polyps in the proximal colon. The cumulative metaanalysis was based on the study prevalence of large lesions and on a random-effect model. The analysis shows how the overall estimate changes as studies with increasing prevalence of large lesions are added to the pool. Each study was added to the next one, and the summary effect was calculated at each step. Results from the cumulative meta-analysis suggest that studies with large lesions may overestimate the effect of clip in lowering the risk of PPB in the proximal colon.

Author(s) and Year

Risk Ratio [95\% Cl]

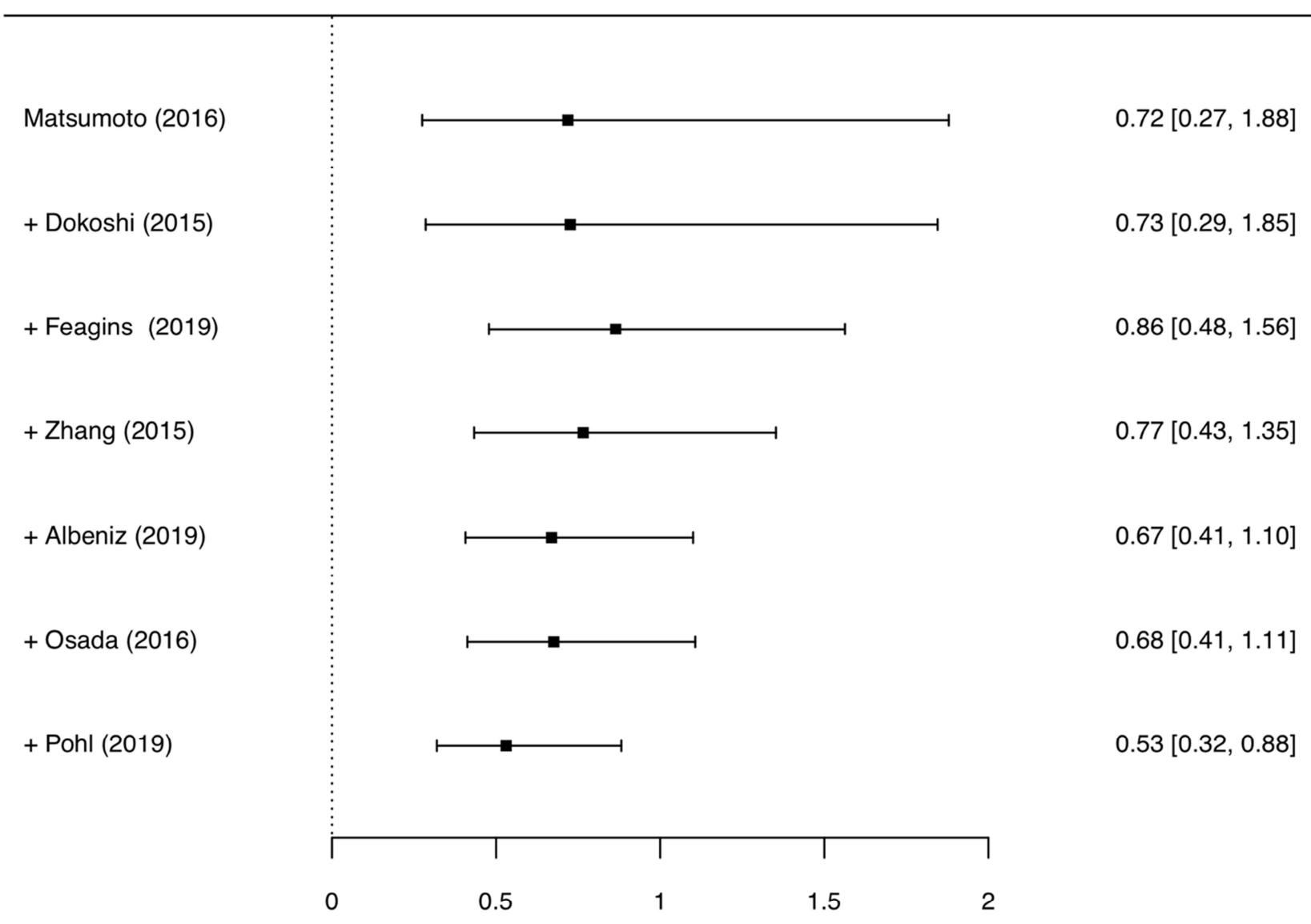

Risk Ratio 
Appendix 3, Supplementary Figure 10 - A) Forest plot, showing the results from a cumulative metaanalysis of the relative risk of PPB for clipped and unclipped polyps in the distal colon. The cumulative meta-analysis was based on the study prevalence of large lesions (descending order) and on a random-effect model. Results from the cumulative meta-analysis suggested that the study by Polh may underestimate the protective effect of clip for large distal lesions. B) A sensitivity analysis excluding the study by Pohl. After excluding this study (in a sensitivity analysis), studies including large lesions demonstrated a significant negative association between clip use and risk of PPB in the distal colon, supporting the hypothesis of a protective effect of clip for large distal polyps (RR:0.28; 95\% CI:0.08-0.97; p=0.044). However, when studies reporting on small lesions were successively added to the analysis, the magnitude of the treatment effect began to increase and became non-significant. Note. Cum. \#, cumulative number of cases.

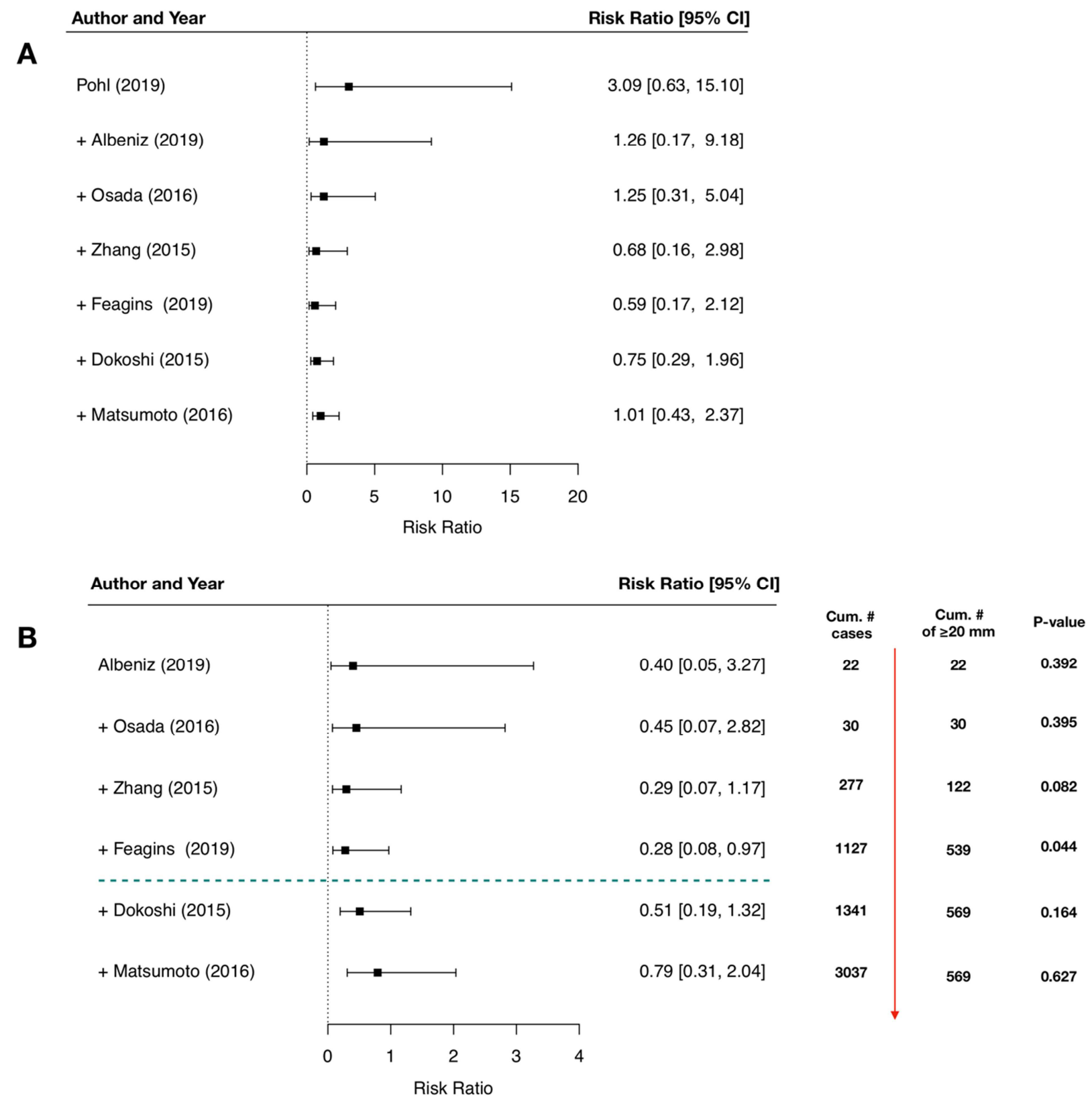




\begin{tabular}{|c|c|c|c|}
\hline Section/topic & $\#$ & Checklist item & $\begin{array}{l}\text { Reported } \\
\text { on page \# }\end{array}$ \\
\hline \multicolumn{4}{|l|}{ TITLE } \\
\hline Title & 1 & Identify the report as a systematic review, meta-analysis, or both. & 1 \\
\hline \multicolumn{4}{|l|}{ ABSTRACT } \\
\hline Structured summary & 2 & $\begin{array}{l}\text { Provide a structured summary including, as applicable: background; objectives; data sources; study eligibility } \\
\text { criteria, participants, and interventions; study appraisal and synthesis methods; results; limitations; conclusions and } \\
\text { implications of key findings; systematic review registration number. }\end{array}$ & 3 \\
\hline \multicolumn{4}{|l|}{ INTRODUCTION } \\
\hline Rationale & 3 & Describe the rationale for the review in the context of what is already known. & 4 \\
\hline Objectives & 4 & $\begin{array}{l}\text { Provide an explicit statement of questions being addressed with reference to participants, interventions, } \\
\text { comparisons, outcomes, and study design (PICOS). }\end{array}$ & 4 \\
\hline \multicolumn{4}{|l|}{ METHODS } \\
\hline Protocol and registration & 5 & $\begin{array}{l}\text { Indicate if a review protocol exists, if and where it can be accessed (e.g., Web address), and, if available, provide } \\
\text { registration information including registration number. }\end{array}$ & 5 \\
\hline Eligibility criteria & 6 & $\begin{array}{l}\text { Specify study characteristics (e.g., PICOS, length of follow-up) and report characteristics (e.g., years considered, } \\
\text { language, publication status) used as criteria for eligibility, giving rationale. }\end{array}$ & 5 \\
\hline Information sources & 7 & $\begin{array}{l}\text { Describe all information sources (e.g., databases with dates of coverage, contact with study authors to identify } \\
\text { additional studies) in the search and date last searched. }\end{array}$ & Appendices \\
\hline Search & 8 & $\begin{array}{l}\text { Present full electronic search strategy for at least one database, including any limits used, such that it could be } \\
\text { repeated. }\end{array}$ & Appendices \\
\hline Study selection & 9 & $\begin{array}{l}\text { State the process for selecting studies (i.e., screening, eligibility, included in systematic review, and, if applicable, } \\
\text { included in the meta-analysis). }\end{array}$ & Appendices \\
\hline Data collection process & 10 & $\begin{array}{l}\text { Describe method of data extraction from reports (e.g., piloted forms, independently, in duplicate) and any } \\
\text { processes for obtaining and confirming data from investigators. }\end{array}$ & Appendices \\
\hline Data items & 11 & $\begin{array}{l}\text { List and define all variables for which data were sought (e.g., PICOS, funding sources) and any assumptions and } \\
\text { simplifications made. }\end{array}$ & Appendices \\
\hline $\begin{array}{l}\text { Risk of bias in individual } \\
\text { studies }\end{array}$ & 12 & $\begin{array}{l}\text { Describe methods used for assessing risk of bias of individual studies (including specification of whether this was } \\
\text { done at the study or outcome level), and how this information is to be used in any data synthesis. }\end{array}$ & Appendices \\
\hline Summary measures & 13 & State the principal summary measures (e.g., risk ratio, difference in means). & 6 \\
\hline Synthesis of results & 14 & $\begin{array}{l}\text { Describe the methods of handling data and combining results of studies, if done, including measures of } \\
\text { consistency }\left(e . g ., I^{2}\right) \text { for each meta-analysis. }\end{array}$ & 6 \\
\hline
\end{tabular}




\begin{tabular}{|c|c|c|c|}
\hline Section/topic & \# & Checklist item & $\begin{array}{l}\text { Reported } \\
\text { on page \# }\end{array}$ \\
\hline Risk of bias across studies & 15 & $\begin{array}{l}\text { Specify any assessment of risk of bias that may affect the cumulative evidence (e.g., publication bias, selective } \\
\text { reporting within studies). }\end{array}$ & Appendices \\
\hline Additional analyses & 16 & $\begin{array}{l}\text { Describe methods of additional analyses (e.g., sensitivity or subgroup analyses, meta-regression), if done, } \\
\text { indicating which were pre-specified. }\end{array}$ & Appendices \\
\hline \multicolumn{4}{|l|}{ RESULTS } \\
\hline Study selection & 17 & $\begin{array}{l}\text { Give numbers of studies screened, assessed for eligibility, and included in the review, with reasons for exclusions } \\
\text { at each stage, ideally with a flow diagram. }\end{array}$ & $8-10$ \\
\hline Study characteristics & 18 & $\begin{array}{l}\text { For each study, present characteristics for which data were extracted (e.g., study size, PICOS, follow-up period) } \\
\text { and provide the citations. }\end{array}$ & $8-10$ \\
\hline Risk of bias within studies & 19 & Present data on risk of bias of each study and, if available, any outcome level assessment (see item 12). & $8-10$ \\
\hline Results of individual studies & 20 & $\begin{array}{l}\text { For all outcomes considered (benefits or harms), present, for each study: (a) simple summary data for each } \\
\text { intervention group (b) effect estimates and confidence intervals, ideally with a forest plot. }\end{array}$ & Figures \\
\hline Synthesis of results & 21 & Present results of each meta-analysis done, including confidence intervals and measures of consistency. & $8-10$ \\
\hline Risk of bias across studies & 22 & Present results of any assessment of risk of bias across studies (see Item 15). & Appendices \\
\hline Additional analysis & 23 & Give results of additional analyses, if done (e.g., sensitivity or subgroup analyses, meta-regression [see Item 16]). & Appendices \\
\hline \multicolumn{4}{|l|}{ DISCUSSION } \\
\hline Summary of evidence & 24 & $\begin{array}{l}\text { Summarize the main findings including the strength of evidence for each main outcome; consider their relevance to } \\
\text { key groups (e.g., healthcare providers, users, and policy makers). }\end{array}$ & $11-12$ \\
\hline Limitations & 25 & $\begin{array}{l}\text { Discuss limitations at study and outcome level (e.g., risk of bias), and at review-level (e.g., incomplete retrieval of } \\
\text { identified research, reporting bias). }\end{array}$ & $11-12$ \\
\hline Conclusions & 26 & Provide a general interpretation of the results in the context of other evidence, and implications for future research. & $11-12$ \\
\hline \multicolumn{4}{|l|}{ FUNDING } \\
\hline Funding & 27 & $\begin{array}{l}\text { Describe sources of funding for the systematic review and other support (e.g., supply of data); role of funders for } \\
\text { the systematic review. }\end{array}$ & 1 \\
\hline
\end{tabular}

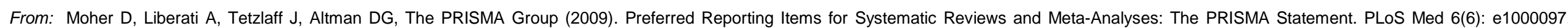
doi:10.1371/journal.pmed1000097 
What you need to know:

Background and Context: It is not clear whether prophylactic clipping prevents bleeding after polypectomy.

New Findings: A meta-analysis of randomized trials showed that routine use of prophylactic clipping does not reduce risk of post-polypectomy bleeding, overall. However, clipping appeared to reduce bleeding after removal of large (more than $20 \mathrm{~mm}$ ) and proximal lesions.

Limitations: This was a meta-analysis of previous studies. Further prospective studies are needed.

Impact: Only large (more than $20 \mathrm{~mm}$ ) and proximal colorectal lesions should be clipped to prevent bleeding after polypectomy.

Lay Summary: This study showed the applying a clip prevents bleeding after removal of large polyps, in specific regions of the colon, but does not prevent bleeding of all polyps overall. 